Portland State University

PDXScholar

5-14-1976

\title{
The Design of an Automatic Electronic Preanodizer
}

Armen C. Grossenbacher

Portland State University

Follow this and additional works at: https://pdxscholar.library.pdx.edu/open_access_etds

Part of the Electrical and Computer Engineering Commons Let us know how access to this document benefits you.

Recommended Citation

Grossenbacher, Armen C., "The Design of an Automatic Electronic Preanodizer" (1976). Dissertations and Theses. Paper 4041.

https://doi.org/10.15760/etd.5925

This Thesis is brought to you for free and open access. It has been accepted for inclusion in Dissertations and Theses by an authorized administrator of PDXScholar. Please contact us if we can make this document more accessible: pdxscholar@pdx.edu. 
AN ABSTRACT OF THE THESIS OF Amnen C, Grossenbacher for the Master of Science in Applied Science presented May 14, 1976.

Title: The Design of an Automatic Electronic Preanodizer.

\section{APPROVED BY MEMBERS OF THE THESIS COMMITTEE:}

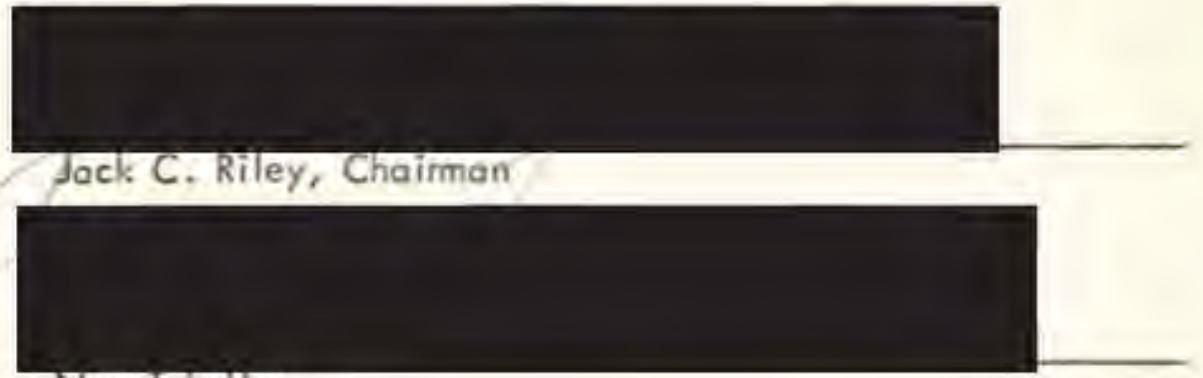

Nan leh Hsu

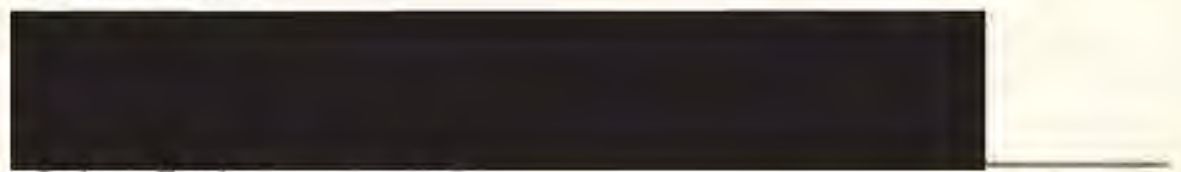

Selmo Tauber

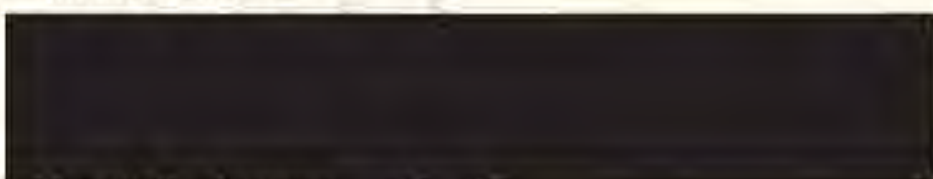

Henfi 15. Joyaux

The topic of this thesis is the design of an autamatic preanodizer to be used to preadiust precision tantalum resistors by anodizing their surfaces. The purpose of the preanodizer is to generate a controllable voltage ramp to be applied to a set of tantalum resistors which are immersed in a suitable electrolyte. The slope and maximum value of the voltage ramp are set tó produce the current required for proper anadization of the resistors. The rate of anodization detemines the rate of change of the resistor value. This thesis covers the design of an electronic device to meet a set of requirements specified by the Western Electric Company. The primary tasks the device has to perform are the generation of a linear voltage ramp of adjustable slope and maximum volfage and the supply of a given maximum 
current. Metering circuits are provided to measure, store and display the current and the maximum value reached by the ramp voltage.

The device contains the logic circuits necessary to start the ramp on operator command. The logic also detects the amplifude of the ramp voltage and stops it when it reaches the value set on a maximum voltage control. The logic circuit lights an error light when the ramp does not complete a normal cycle,

The requirements of the device covered many areas in electronic technology. The author had to do considerable research in these different areas in order to design the necessary circuits. The areas of concern are as follows:

1. Power supply. Involved the study of the characteristics of modern power transformers, rectifier diodes, integrated circuit regulators and filter elements.

2. Power amplifier and preamplifier. Involved the study of power transistor circuits, methods of compounding multiple transistors to withstand the required power and provide sufficient gain, methods of driving the power amplifier and methods of dissipating the heat generated.

3. Ramp generator. Involved the study of function generation circuits and their control.

4. Metering circuits. Involved the study of sample and hold circuits and operational amplifier scaling circuits.

5. Logic circuits. Involved the study of various logic families and the decision making and switching methods that could be accomplished.

The design was completed and a production run of ten units was made. A calibration and test procedure was written in order to test the various circuits over a wide range of input voltages and ambient temperature. The tests were run on the production quantity of ten units. All ten units passed all requirements with a safety factor of 2 or more. The units have been in doily operation at the Western Electric plant for approximately two years. To this date none of the units have foiled. The Western Electric Compony is pleased and the designer is quite happy to have achieved this measure of success with his project. 


\section{TO THE OFFICE OF GRADUATE STUDIES AND RESEARCH:}

The inembers of the Cormillee approve the thesis of Armen C. Grossenbacher presesied May 14, 1976.

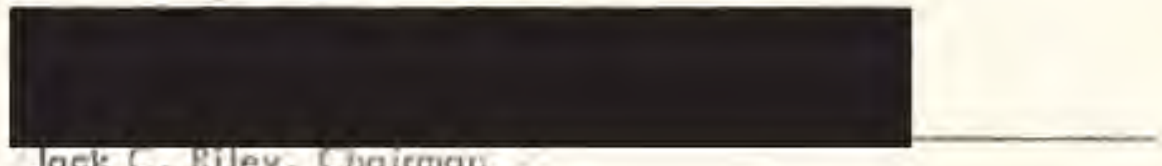

Jack C, Riley, Chaiman

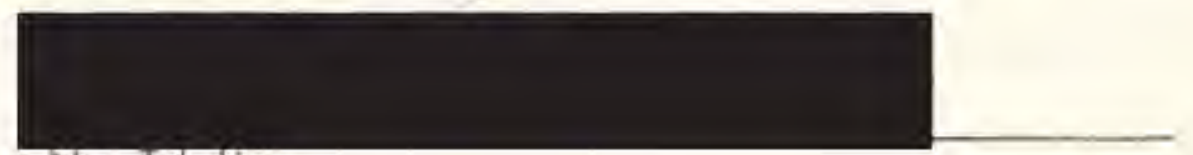

Nan teh Hsu

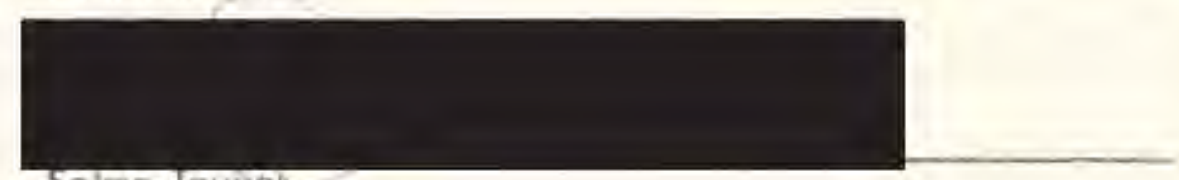

Selmo laviely.

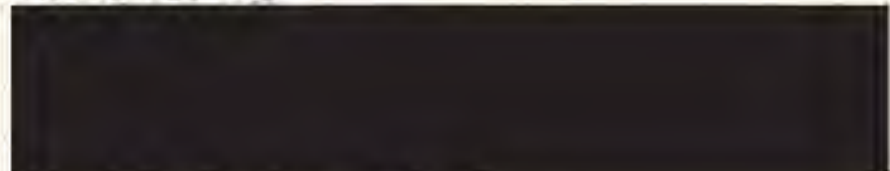

Hanti B, Joyaux

\section{APPROVED:}

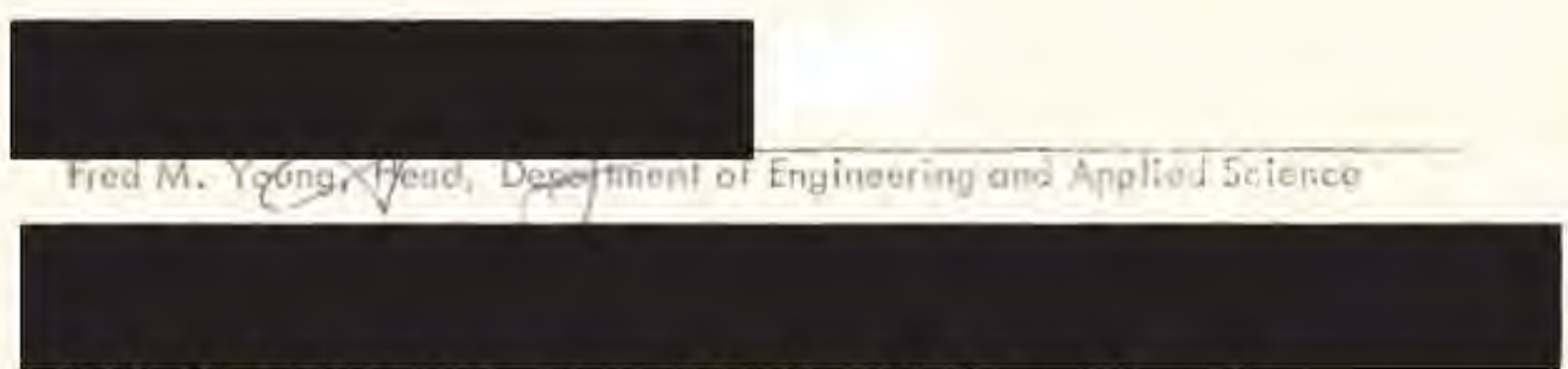

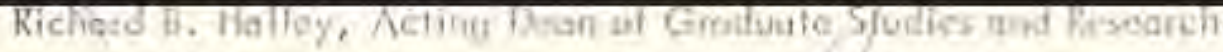


TABLE OF CONTENTS

PAGE

LIST OF FIGURES ........................

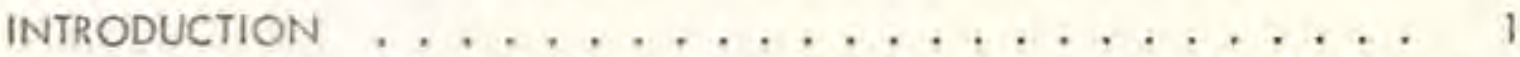

THE TANTALUM RESISTOR . . . . . . . . . . . . . . 4

I DESCRIPTION OF TANTALUM RESISTOR FABRICATION . . 4

II DESCRIPTION OF THE PRODUCTION EQUIPMENT ..... 6

REQUIREMENTS AND SPECIFICATIONS ............ 7

DESIGN OF NECESSARY CIRCUITS $\ldots \ldots \ldots \ldots$

I POWER SUPPLY .................. 9

Power Transformer Selection ........... . 9

Diode Bridge Rectifier (CR5) Requiremants . . . . . 12

Filter Capacitar Requirements. . . . . . . . . . 12

II POWER AMPLIFIER .................. 13

Selection of Power Transistors . . . . . . . 16

Selection of Heat Sinking Methods. . . . . . . . 16

Power Amplifier Circuit . . . . . . . . . 20

III PREAMPLIFIER AND CURRENT CLAMP $\ldots \ldots, \ldots, 22$

Preamplifier ............... 22

Current Clamping Circuit .......... 25

Two Amp Clamp Cireuit . . . . . . . . . . 25

One Amp Clemp Circuit ........... 25

IV INTEGRATOR (RAMP GENERATQR) ........... 27

V CURRENT AND VOLTAGE METERING CIRCUITS . . . . . . 29

Current Metering . . , , , . . . . . . . . . 29

Voltage Metering .............. 33

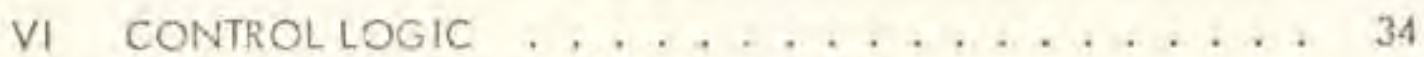


PAGE

CALIBRATION AND FINAL EVALUATION OF PREANODIZER . . . . . 40

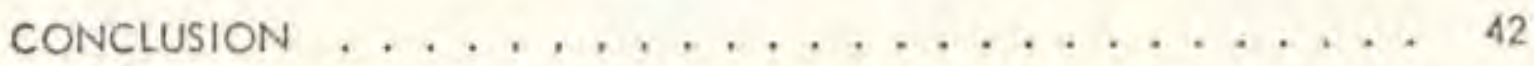

SIBLIOGRAPHY ,...................... 43 


\section{LIST OF FIGURES}

FIGURE

PAGE

1. Resistor being anodized .............. 5

2. Growth rate versus current density ........... 5

3. Outline drawing of preanodizer ............. 2

4. Maximum operating areas for type 2 N6259 . . . . . . . 17

5. Thermal-cycle rating chart for type 2 N6259 ... . . . 18

6. Typical de beta characteristics for type 2 N6259 . . . . . 18

7. Typical output characieristics for type 2 N6259 ....... 11

8. Typical saturation-voltage characteristics for type $2 \mathrm{~N} 6259, \ldots, 11$

9. Thermal analogy to Ohm's Law ............. 19

10. Junction to ambient temperature distribution of transistor . . . 19

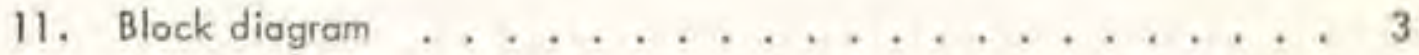

12. Power amplifier assembly $\ldots \ldots \ldots . . . . . .14$

13. Preamplifier circuit assembly ............. 15

14, Integrator circuit assembly .............. 28

15. Metering amplifier $\mathrm{PCB}$ assembly ............ 30

16. Sample and hold $\times 10$ (relay) PCB assembly ......... 31

17. Logic board circuil assembly . . . . . . . . . . 35

18. Crosspoint sconner PCB assembly............ 36

19. Calibration procedure .............. 41 


\section{INTRODUCTION}

The subject of this thesis it an electronic device called an autamatic preanodizer ESI model SP 3699, which is an occessary to the ESI model SP 3477 anodizing system designed and produced by Electro Scientific industries for the Western Electric Company. The system is used to adjust the value of tantalum resistors by precision anodization of their surfoces. The purpose of the preanodizer is to make a preliminary adjustment of the resistors. The preanodizer was assigned to A. C. Grassenbacher as an engineering design project. See Figure 3 for an outline drawing, and Figure 11, page 3, for a block diagram, of the unit. The preanodizer generates a controllable voltage ramp to be applied to a set of tantalum resistors which are immersed in a suitable electrolyte. The slope and maximum volue of the voltoge ramp are set to produce the current required for proper anodization. The rate of anodization determines the rate of change of the resistor value.

The design objectives were determined from requirements set by the Western Electric Company. Additional requirements were considered necessary for equipment safety and product protection. Among these added feotures are two levels of current limiting, voltage foldback at the current limit and an error mode providing indications of improper preanodization such as a short circuited load. 

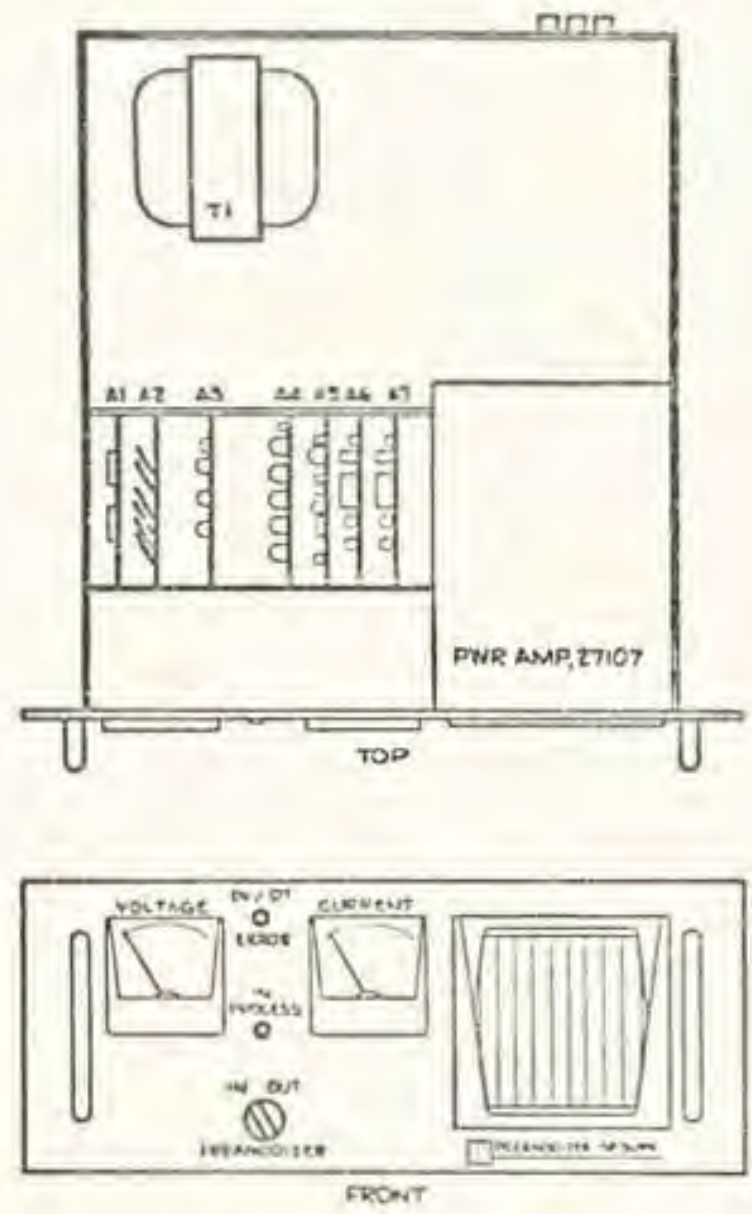

NOTE:

A) Cooss noint scavenge, 2300

21. PDE AND $27 \mathrm{MA}$.

AS inteGRATCR, 27ROS

4 wDGic 2710

AS NIterass CKT, 29057

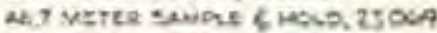

Figure 3. Oufline drawing of preanodizer 


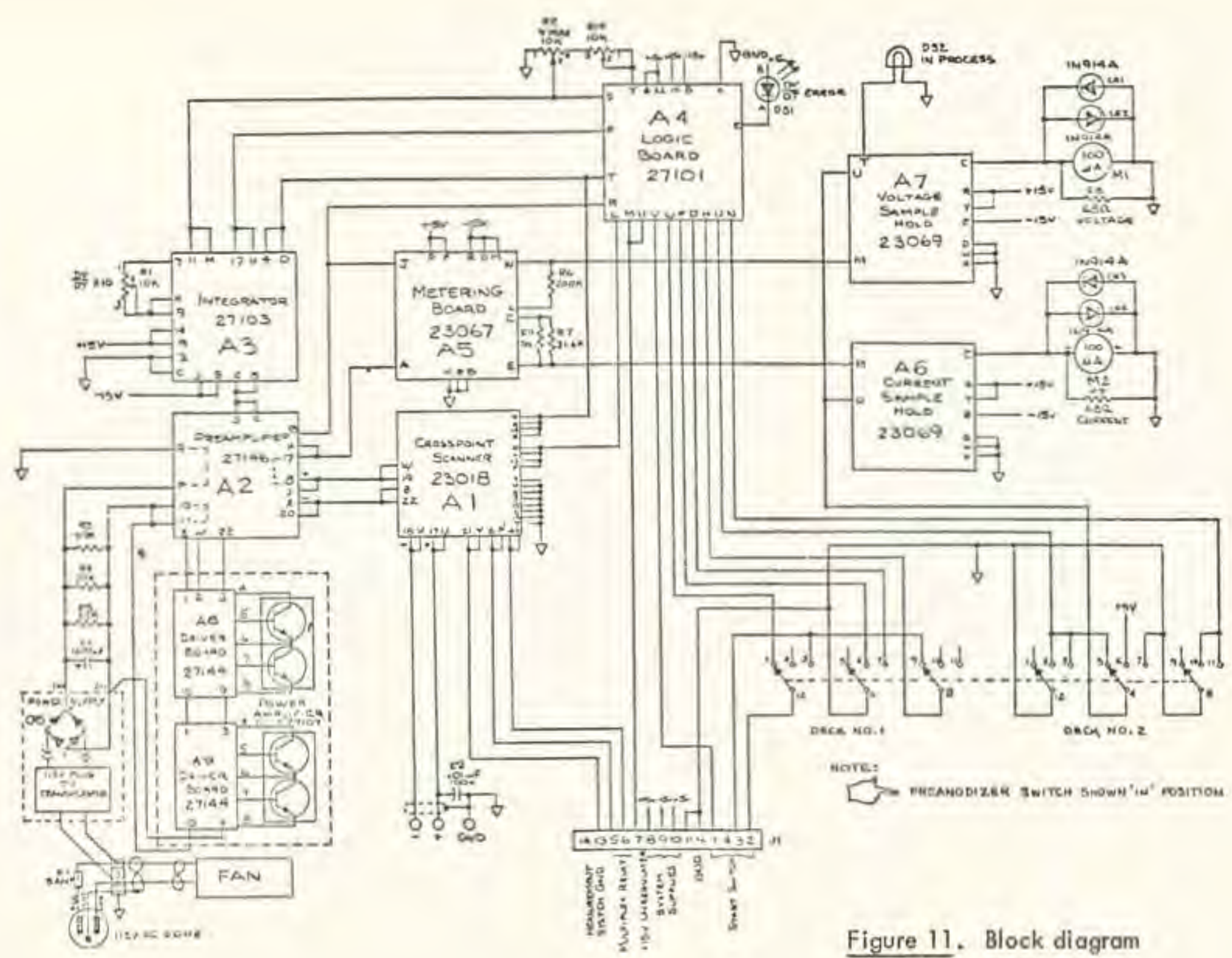




\section{THE TANTALUM RESISTOR}

The Western Electric Company collaborating closely with scientists of Bell Telephone Laboratories have developed a high volume manufacturing method for the production of precision tanfalum thin film resistors and capacitors. Tantalum technology complements the silicon technology used for the production of transistors, diodes and now critical resistors on integrated circuits, Berry, Hall and Harris (1). These two technologies have made possible the mass production of integrated circuits, active filters and tuned amplifiers used in communication devices such as the fouch-tone telephone.

\section{DESCRIPTION OF TANTALUM RESISTOR FABRICATION}

The resistor is fabricated by depositing a thin film of tantalum or tantolum nitride on an insulating substrate such as ceramic. The deposition is made approximately $30 \%$ thicker than calculated so that all resistors will have a resistance lower than the desired value. An electrolytic paste is then applied to the resistor surface and de current is passed through the electrolyte and the tantalum resistor as shown in Figure 1. This current converts the resistor's surface to an insulating oxide. This process is called anodization and it produces two desirable qualities:

1. The resistance value is increased because as the surface is being converted to an insulating oxide, the conduction path is made thinner. The increase in oxide formation (and resistance value) is closely related to the current density and the time the current is allowed to flow as shown in Figure 2. The value of the resistor can be precisely adjusted by corefully controlling these two parameters.

2. The surface is protecred because the volume of oxide formed by the anadization process for both tantalurn and tantalum nitride materials exceeds the volume of the original material involved in the conversion as shown in Figure 2. A layor of a lightly knit molecular structure is produced which serves as on excellent finsulating profective coating on the resistor's surface. 


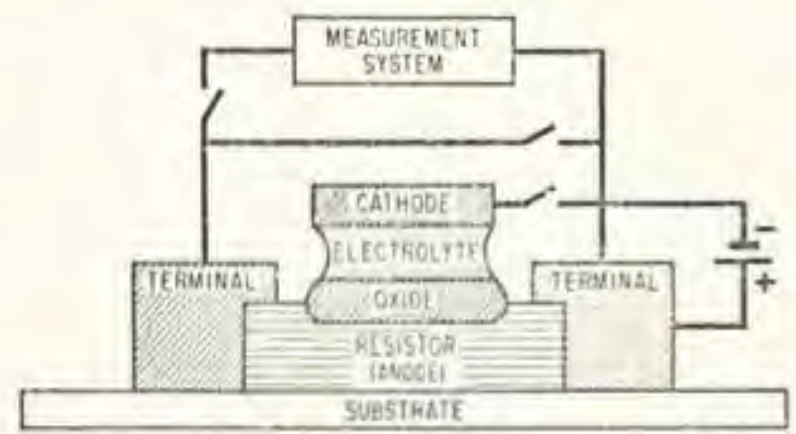

Figure 1. Resistor being anodized

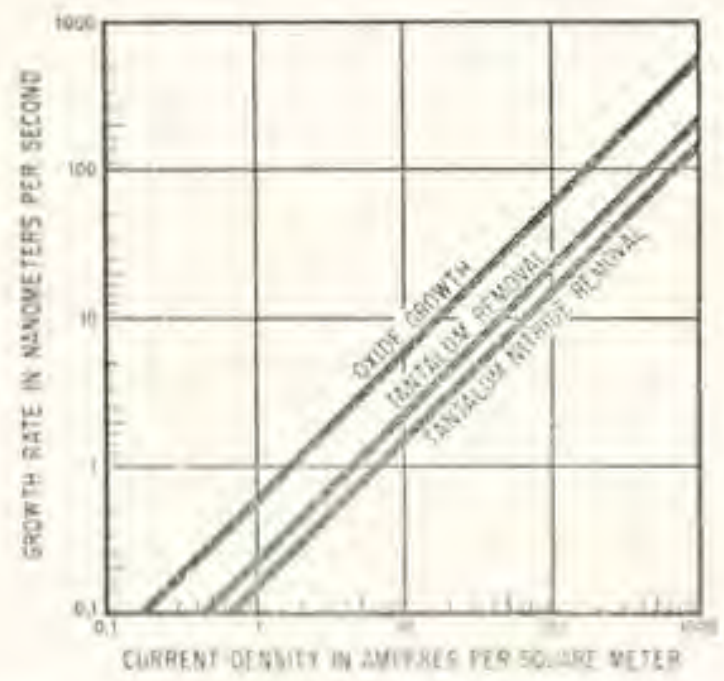

Figure 2. Growth rate versus current density 
The typical resistors are 70 to 250 nonometers thick. The anodization process produces $\mathrm{Ta}_{2} \mathrm{O}_{5}$ at a rate of ane oxide malecule for each ten electrons removed. Thus the rate of axide formation is direclly related to current density and time. The volume conversion rates for a one coulomb charge (one ampere-second) are $0.023 \mathrm{~mm}^{3}$ of metal converted to $0.057 \mathrm{~mm}^{3}$ of oxide for pure tantalum and $0.025 \mathrm{~mm}^{3}$ of metal converted $100.09 \mathrm{~mm}^{3}$ of oxide for tontalum nitride.

\section{DESCRIPTION OF THE PRODUCTION EQUIPMENT}

The design requirements for the anodization equipment were to measure and adjust these resistors to tolerances of $2 \%$ at a rafe of four per second and to a tolerance of $0.01 \%$ at a rate of one per second.

These resistors are on a ceramic substrate approximaiely $4 \mathrm{~cm}$ by $8 \mathrm{~cm}$. Eoch substrate has up to ten resistors and several capacitors which serve as funing elements for frequency filters. Up to 20 of these substrates are connected at one time. An electrolyte is applied to the resistors through a suitable mask. The substrates are placed in a fixture with probes connecting each resistor to the measuring and adjusting system. At the start of the sequence up to 200 resistors are relay switched to the preanodizer (the subject of the thesis) which applies a vo!toge ramp, which is controllable in amplitude and time duration. This voltage ramp creates a constant current for a definite time period through all of the resistors to produce on initial anodized layer. This anodized layer brings all of the resistors to within measurement range of the main anodizing system. At the end of the preanodizing cycle the preanodizer outomatically switches the entire batch of resisfors to the main system where each resistor is relay switched to o resistance measuring system under computer control. The computer compares the ineasured value with the desired value stored in lts memory and determines an onodizing current and time required to bring the resistance up to volue. The computer sets these values into a time and amplitude controlled current source. The relays next switch the progrommed current source to the resistor. The computer then sequences the measuring system to the next resistor. This proeess is continued through all of the resisfors with on end of process signal indicating when all the resistors are within their tolerance linits. 


\section{REQUIREMENTS AND SPECIFICATIONS}

The preanodizer was designed to meet the following requirements and specifications as set forth by the Western Electric Company. See Figure II, page 3, for a block diagram.

1. Produce a voltage ramp that is variable in rate from 150 volts per minute to 2500 volts per minute with an accuracy of $\pm 5 \%$.

2. Provide an adjustable maximum voltage limit such that the vollage reached by the ramp can be set from zero to -100 volts with an accuracy of $\pm 5 \%$.

3. Provide sample and hold circuits to store the maximum load voltage and current reached during the preanodizing cycle and feed these values to front panel meters for display with an accuracy of $\pm 3 \%$.

4. Provide a current limiting eircuit such that the maximum current during a normal preanodizing cycle will be 2 amperes but will diop to 1 ampere maximum in case of a load resistance which is so low that the voltage cannot be followed at a load current of 2 amperes. This requirement allows a fantalum resistor, or group of them, which starts with a very low surface resistance, to be anodized with a lower current level. As the anodized layer builds, the surface resistance increoses and the current limiting circuits can return to normal.

5. Provide relay switching so that the resistors being onodized are switched to the preanodizer during its cycle, then switched back to the multiplexer of the ESI model SP 3477.

6. Provide a circuit that will detect when the preanodizing cycle was not successfully completed, i.e., the maximum ramp voltage was never reached due to a load resislance ton low to support the ranip voltoge at the current limit values. This circuit monitors the output voltage ramp and allows a time of $20 \%$ longer than normal for the ramp to reach $V$ maximum. If the ramp fails lo reoch $V$ maximum the circuit 
lights an error lamp indicating a dV/dt error and stops the cycle without transferring the leads to the ESI model SP 3477 . This allows the operator fo defermine the cause of error by noting the values of voliage and current held by the meters, and to take appiopriate action.

7. Provide a front ponel control that will switch the preanodizer into or out of the process. When switched out the meters on the preanodizer must be refurned to zero and the $d V / d t$ error light must be extinguished if lit.

The above requirements were all met and in most coses exceeded by the device described in this thesis. 


\section{DESIGN OF NECESSARY CIRCUITS}

The circuits necesscry to perform the preanodizing function are discussed in the following subsections.

Subsection I, POWER SUPPLY, discusses the power supply that converts the line voltage of 117 volts rms to the de voltages required by the power amplifier.

Subsection II, POWER AMPLIFIER, discusses the power amplifier that controls the current and voltage applied to the load.

Subsection III, PREAMPLIFIER AND CURRENT CLAMP, discusses the preamplifier necessary to provide the amplification required between the ramp generator and the power amplifier.

Subsection IV, INTEGRATOR (RAMP GENERATOR), discusses the integrator which generates the ramp voltage of a preset amplitude and slope.

Subsection V, CURRENT AND VOLTAGE METERING CIRCUITS, discussos the current and voltage metering circuits.

Subsection VI, CONTROL LOGIC, discusses the logic required to control the various sections of the preanodizer.

\section{FOWER SUPPLY}

See Figure 11, page 3 . The regulated \pm 15 volts required by the operational amplifiers and the regulated 5 volts required by the logic are oblained externally. The power supply in the preanodizer needs to supply only the power requirements of the load through the power amplifier.

The requirements on the power supply are that it be able to deliver a maximum current of 2 omperes to the load at a maxirum voltage of 100 volts dc.

\section{Power Transformer Selection}

The rms output volfage of the power tronsformer is calculated on the basis of insuring 100 volis de across the load at maximum load current with low line vollage, considering the output transistor drou ond the percent load regulation 
allowed by the filter capacitor. Assume the following conditions:

1. The de output of a capocitor filtered power supply is $\sqrt{2}$ times the mis valtage applied.

2. Low line volfage $=100 \mathrm{~V}$,

3. The fotal volloge drop across the four series-connected output transistors is 4 times the individual saturation voltage of each one with 2 amperes flowing. Figure 8 is the curve of saturation volfage versus collector current for the 2 N6259 transistor. It shows a safuration voltage less than 0.2 volt at 2 amperes. For this analysis we vill conservatively use 0.5 volt per fransistor giving 2 volts fotal for the four in series.

4. The transformer resistance is less than 5 ohms.

5. The output stoge has been designed as an emitter follower so that any reasonable variation in collector valtage will not be present across the load. This can be verified by looking at Figure 7 of the 2 N6259 transistor curves and nofing that the change in collector curtent versus collector voltoge around 2 amperes is approximately $10 \%$. The load regulation allowed by the filter capacitor can then be $5 e 1$ at $10 \%$. This would yield a change in load current versos filter characteristics of $10 \%$ of $10 \%$ or $1 \%$ which is well within the design requirements.

The tronsformer output voltoge can now be calculated, Boylestad and Washelsky (2), as:

$$
\begin{aligned}
& V_{L}=\sqrt{2} V_{T}\left(1-E_{T}\right)-V_{Q}-I_{L} R_{T}-V_{R} \\
& V_{T}=80.19 \mathrm{~V}
\end{aligned}
$$

where

$$
\begin{aligned}
& V_{L} \quad \text { - Load voltage loov de } \\
& V_{T} \quad \text { - Transformer open-circuit output voltage in volts rms } \\
& E_{T} \quad \text { - Transformer loss } 0.1 \text { proporitional parts }(10 \%) \\
& V_{Q} \quad \text { - Trensistor vollage drop } 2 \mathrm{~V} \mathrm{da} \\
& I_{L} \quad \text { - Full load current } 2 \mathrm{~A} \text { de }
\end{aligned}
$$




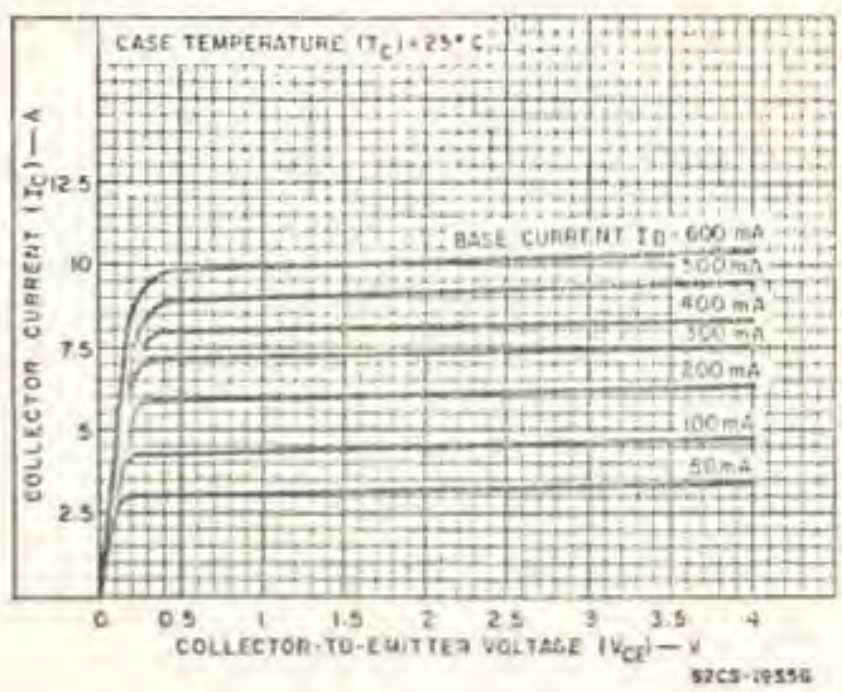

Figute 7. Typical output characteristics for type 2 N6259

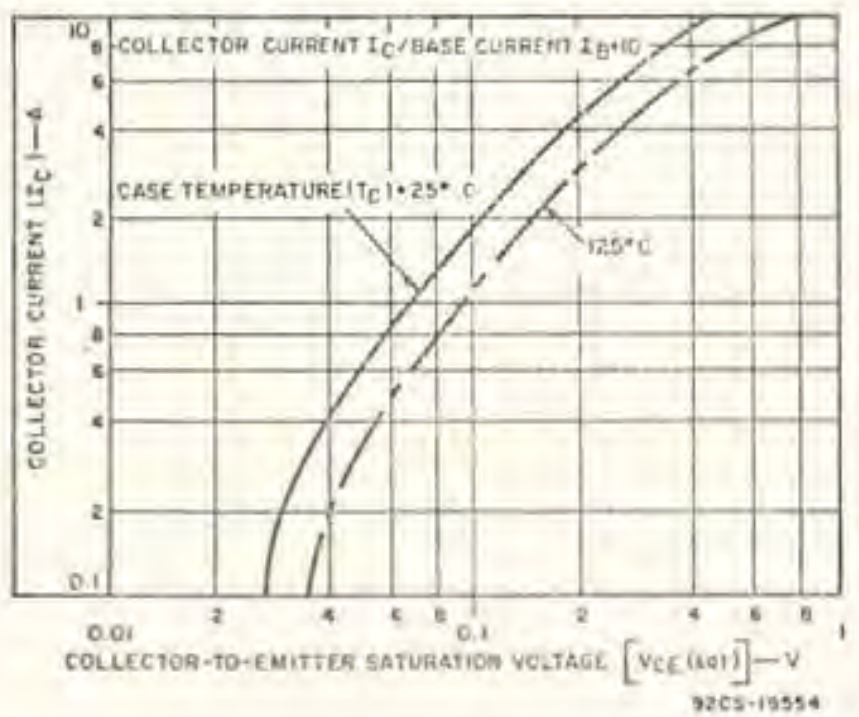

Figure 8. Typical saturation-voltoge characteristics for type 2N6259 


$$
\begin{aligned}
& R_{T} \quad \text { - Transformer winding resistance } 5 \Omega \\
& V_{R} \quad \text { - Rectifier valtage drop } 1.5 \mathrm{~V} \text { dc }
\end{aligned}
$$

The transformer can then be a one to one ratio which will yield 89.2 volts at a low line voltage of 100 volts at $89.2 \%$ transformer efficiency. The unit selected to meet the requirements is a Stancor model P 6415 which has the following specifications:

1. A transformer ratio of 1.07 to 1 giving 107 volts out with 100 volts in, This would yield 89.12 volts out with 100 volts in at $83 \%$ efficiency.

2. Secondary resistance of 3.15 ohms.

3. Current output of 3 amperes of 117 volts and 350 watts.

\section{Diode Bridge Rectifier (CR5) Requirements}

The diode bridge rectifier must provide 2 amperes continuous current with a maximum de voltage drop of less than 1.5 volts and must be able to withstand a reverse voltage of $\sqrt{2}$ times the rms value of the highest line voltage encountered. Assuming 130 volts to be a maximum line voltage, the inverse voltage would be:

$$
V \text { inverse }=1.414 \times 130 \mathrm{~V}=183.82 \mathrm{~V} \mathrm{dc}
$$

The rectifier selected was the Motorola MDA 952-4 silicon bridge rectifier which has 6 amperes continuous forward current, 1.3 volts forward drop at 2 amperes and a reverse voltage rating of 400 volts.

\section{Filter Capacilor Requirements}

The filter capacitor must provide a voltage change of less than $10 \%$ at the rated eurrent drain of 2 amperes. The capacitor must provide the 2 amperes to the load during the periods between diode conduction which is approximately 8 milliseconds for a full wave rectifier producing pulsatina de at a frequency of $120 \mathrm{~Hz}$. The capacitor value is calculated, Radio Corporation of America (3), as follows:

where

$$
\text { I } C=C \frac{d V}{d t} K
$$

$$
\text { IC - Lood current supplient 2A dis }
$$




$$
\begin{aligned}
& \text { C } \quad \text { - Copacitor capacitance in farads } \\
& d V / d t \text { - Time rate of change of voltage }(1 / 8) \times 10^{5} \mathrm{~V} / \mathrm{s} \\
& K \quad \text { - Permitted voltage drop } 0.1 \mathrm{~V} / \mathrm{V}
\end{aligned}
$$

therefore

$$
\mathrm{C}=1600 \mu \mathrm{F}
$$

A bleeder resistance of 13 kilohms was connected across the filter capacitor. This allows the power supply to discharge to approximately 37 volts in 20 seconds (one RC time of $(13)\left(10^{3}\right)(1600)\left(10^{-6}\right)=20$ seconds). This is fost enough to allow protection to a service person gaining entry to the unit.

\section{If POWER AMPLIFIER}

Refer to Figure 12, power amplifier and Figure 13, page 15, preamplifier.

Several types of power amplifier circuits were considered before the final design was chosen.

Two general types of circuits presented in the literature, Radio Corporation of America (3) and Cutler (5), were finally singled out for final consideration. One type is a common-emitter connection which provides the output from the collectors of the output transistors. This type of circuit provides an excellent isolation of the load from the power amplifier because of its high collector impedances and would be thus an excellent choice for a current output application. The preanodizer, however, requires that the oulpuf be a linear voltage ramp rather than a eurrent ramp. This voltage ramp could have been achieved with suitable negative feedback from the load to the preamplifier input. This method was tried but rejected because the load could consist of not only fairly low resistance but of a fairly high copacitance. When this capacitance was simulated the phase of the feedbock back loop shifted far enough for the circuit to oscillate.

The other type of power amplifier eireuit, which was the ehoice for this project, is colled an emitter follower. The load is placed in the emitter circuit and the collector is held at signal common. The output voltage across the load now follows the variation of input voltage applied to the bases within one emitter base diode voltage drop. All negative feedback required for stability and signal linearlty can now be done in the preamplifier which provides isolation from the copacitance and assures stability. 

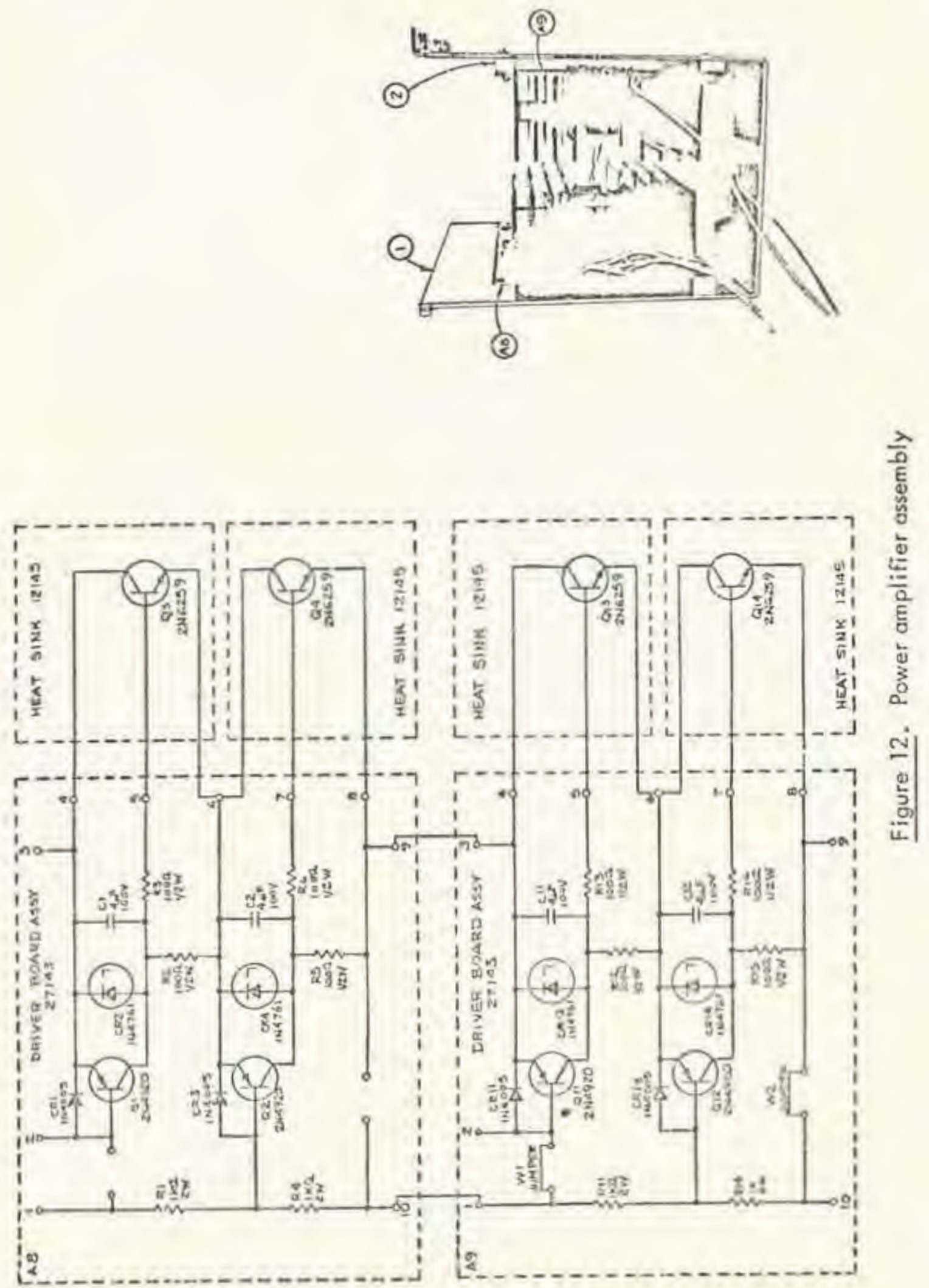


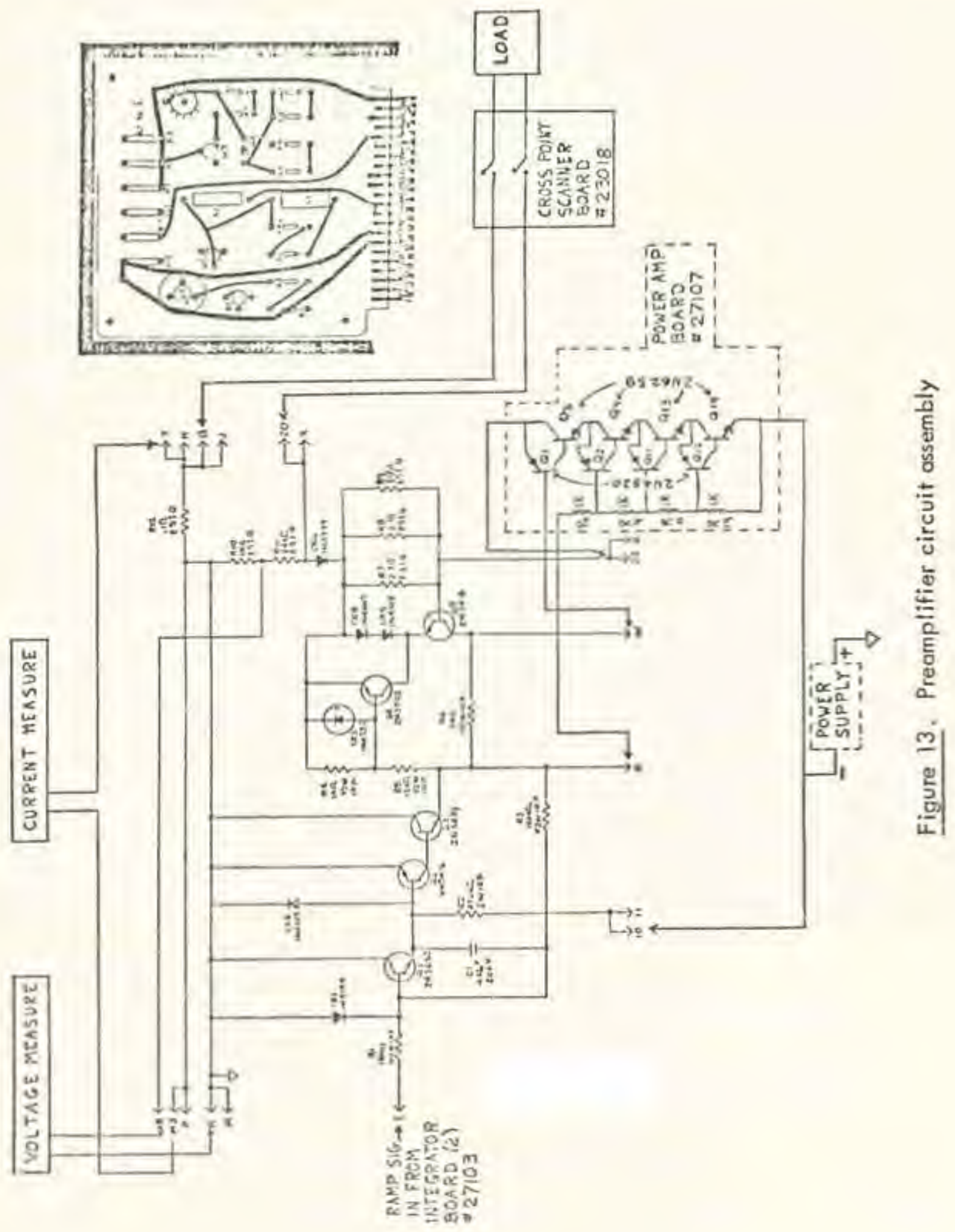




\section{Selection of Power Transistors}

The power that must be dissipated in the power/amplifier transistors is maximum at the start of the ramp. At this point there could be as much as two amperes of current flowing with all the power supply voltage dropped across the power leansistors. If we assume a maximum line voltage of 135 volts, the maximum power the transistors would dissipate is:

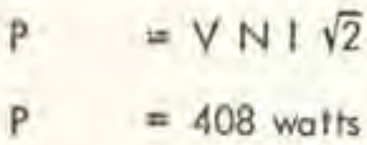

where

$$
\begin{array}{lll}
\text { P } & \text { - Maximum transistor power dissipation in watts } \\
\text { V } & \text { - Maximum line voltage } & 135 \mathrm{~V} \mathrm{cms} \\
\mathrm{N} & \text { - Transformer furns ratio } & 1.07 \\
\text { I } & \text { - Maximum current } & 2 \mathrm{Adc}
\end{array}
$$

A single transistor capable of dissipating 408 warts would be much too expensive. Multiple transistor circuits which would distribute the power dissipation among saveral transistors were studied. Connecting transistors in parallel to reduce the current flow through each fransistor was not practical in this design because of the high voltages ( 204 volts) involved. The method chosen was to use four transistors in series to reduce the voltage drop across each to approximately 51 volts maximum. At 2 amperes this is a power dissipation requirement of 102 watts maximum per transistor. The transistor selected was the RCA 2 N6259 which is capable of 250 watts dissipation if the case is kept at $25^{\circ} \mathrm{C}$ as seen in Figure 4 .

\section{Selection of Heat Sinking Methods}

Since it is impractical to remove all the heat from the device so that is temperature would renain at $25^{\circ} \mathrm{C}$, we must determine what temperature can be allawed, The transistor junction temperature cannot go above $200^{\circ} \mathrm{C}$, Figure 5 , page 18, without damage af the required power dissipation of 102 watts inaximum.

The heot sinking requirements are determined by use of the thermal analogy 10 Ohrn's Low shown in Figures 9 and 10, page 19. From this analogy we sen that the junetion temperofure is: 


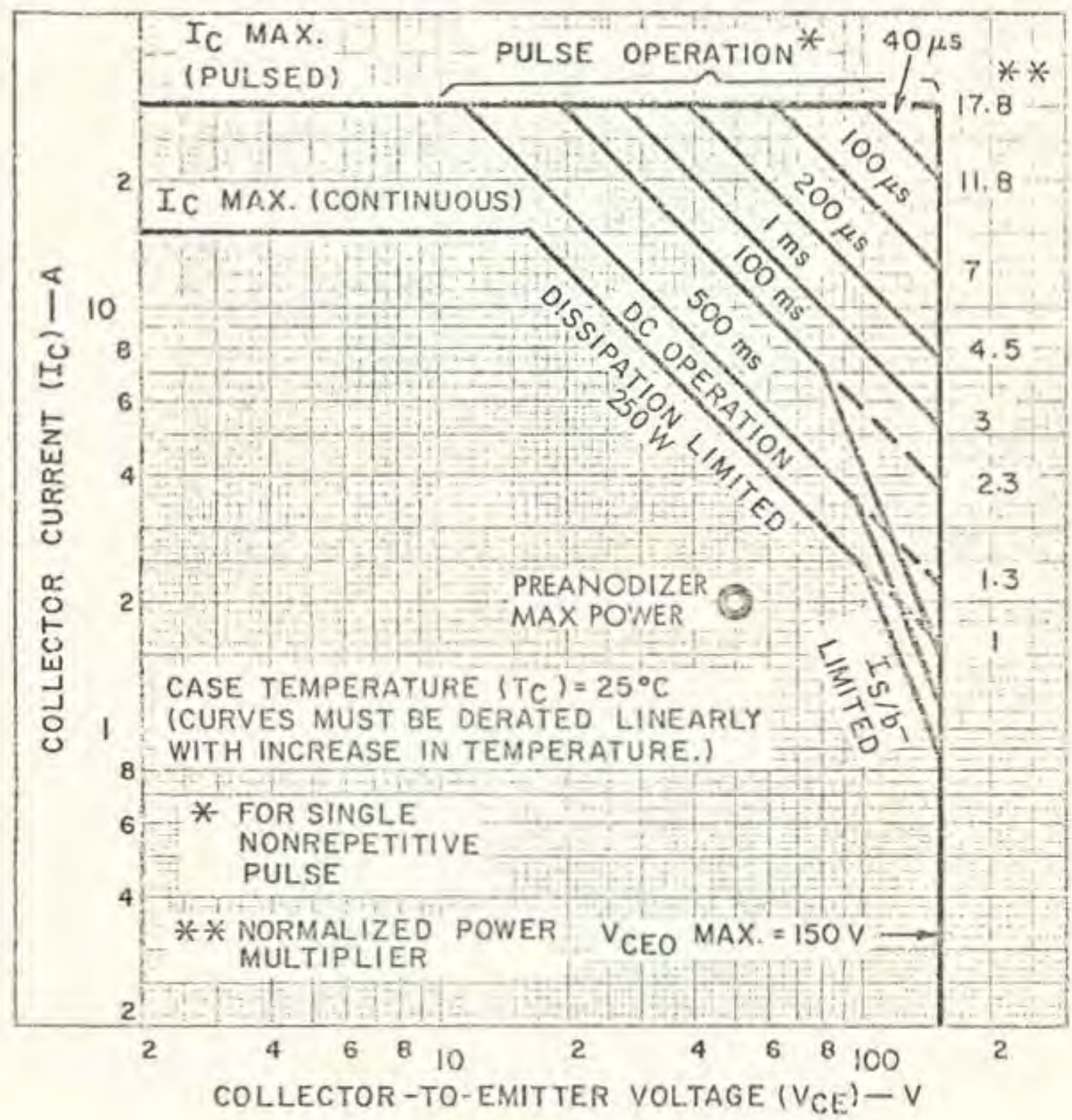

Figure 4. Maximum operating areas for type 2N6259 


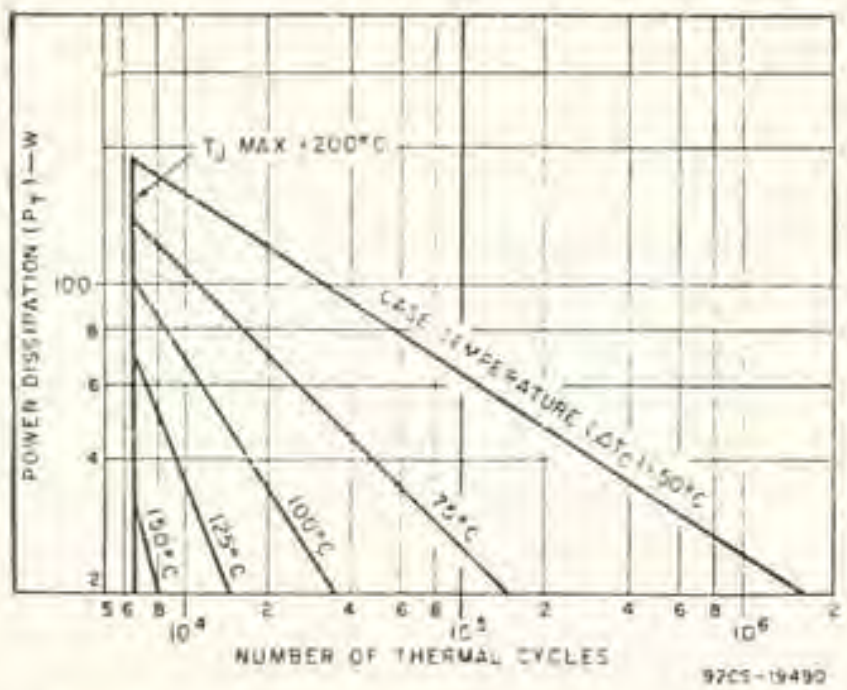

Figure 5, Thermal-cycle rating chart for type $2 \mathrm{~N} 6259$

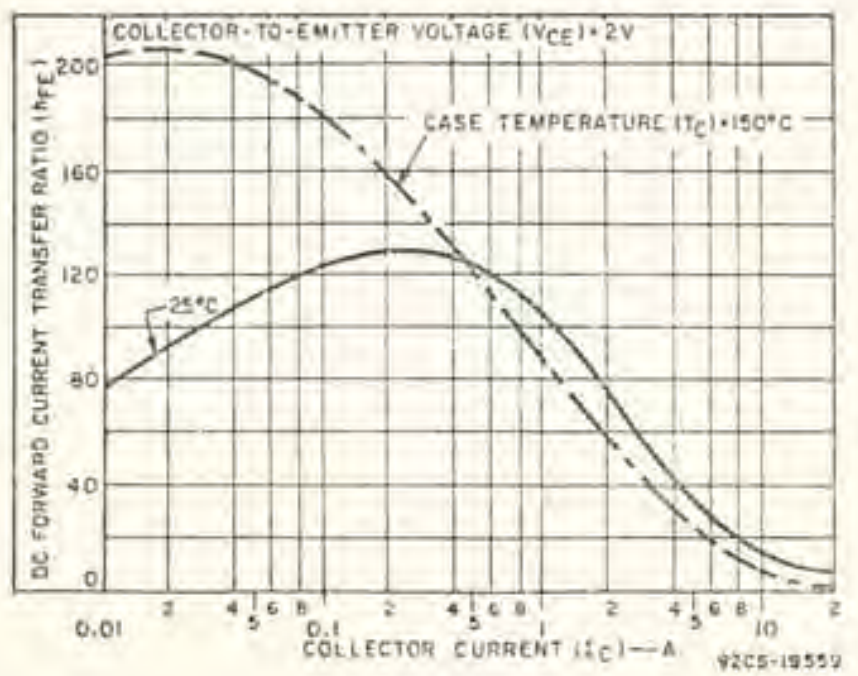

Figure 6. Typical dc beta characteristics for type 2 N6259 


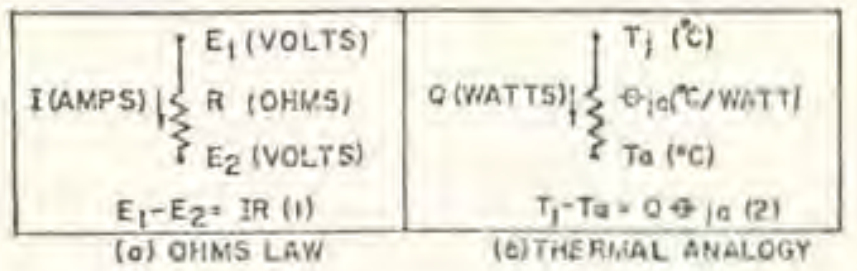

Figure 9. Thermal analogy to Ohm's Law

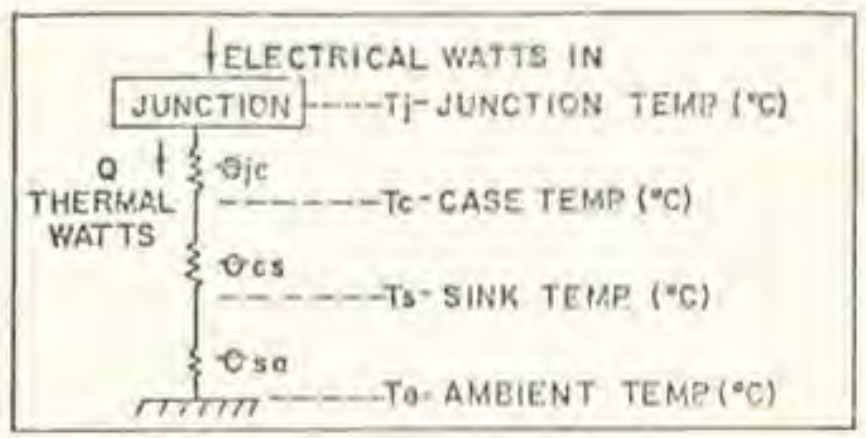

Figure 10. Junction to ambient temperature distribution of fransistor 


$$
T_{i}=T_{a}+P\left(\theta_{i c}+\theta_{c s}+\theta_{s a}\right)
$$

where

$$
\begin{array}{ll}
p & \text { - Power dissipated in watts } \\
\theta_{i c} & \text { - Thermal resistance of iunction to case } \\
\theta_{c s} & \text { - Thermal resistance case to sink } \\
\theta_{\text {sa }} & \text { - Thermal resistance of sink to ambient }
\end{array}
$$

The thermal resistance $\left(\theta_{i c}\right)$ for a $2 \mathrm{~N} 6259$ transistor is $0.7^{\circ} \mathrm{C}$ per walt. Using mica insulators and heat sink grease to mount the transistor to the heaf sink yields a case to sink thermal resistance $\left(\theta_{c s}\right)$ of approximately $0.5^{\circ} \mathrm{C}$ per watt. The ambient temperature of the area the preanodizer is to operote in would not exceed $30^{\circ} \mathrm{C}$. The heat sink thermal resistance is colculated as follows:

$$
\begin{aligned}
\theta_{\text {sa }} & =\frac{T_{i}-T_{a}}{P_{\text {max }}}-\theta_{i c}-\theta_{c s} \\
& =\frac{\left(200^{\circ}-30^{\circ}\right) C}{102 \text { watis }}-(0.7+0.5)^{\circ} C \text { per watt } \\
& =0.5^{\circ} \mathrm{C} \text { per wall }
\end{aligned}
$$

The heat sink chosen was a Wakefield model NC413 for each transistor. These were mounted in a sheet metal funnel with a Rotron model 174 fan blowing air at 100 cubic feet per minute through the tunnel over the sinks as seen in Figure 12, page 14. This combination provides a $\theta_{\text {sa }}$ of less than $0.25^{\circ} \mathrm{C}$ per watt which provides a two times safety factor over the requirement.

\section{Power Amplifier Circuit}

The input base drive ourrent required for a $2 \mathrm{Nb} 259$ is determined from the curves of $\mathrm{H}_{\text {fe }}$ shown in Figure 6, poge 18. From Figure 6 the current transfer ratio for an outaut current of 2 amperes is 80 . In this design an $\mathrm{H}_{\mathrm{fe}}$ of 50 was assumed to be conservative. The input tase drive current required is then:

$$
\text { I base }=\frac{\text { I collector }}{H_{\text {fe }}}=\frac{2 \text { amperes }}{50}=40 \mathrm{ma}
$$


In order to reduce the current drive requirements of the preamplifier it was decided to provide the base current for each power transistor from a separate $2 \mathrm{~N} 4920$ transistor, as shown in Figure 12, page 14, and Figure 13, page 15. This method of direct couple driving is called a compound feedback pair, Cowles (4), of which there are several choices. This compound pair was chosen over the usual Darlington connection because it has only one diode voltage drop between the input base circuit and the load in the emitter follower circuit yet still provides the product of the individual transistor current gains as a total circuit current gain. The minimum $\mathrm{H}_{\mathrm{fe}}$ for the driver transistor, $2 \mathrm{~N} 4920$, for 40 milliemperes of collecfor current is 40 . The input drive current for each compound pair for 2 amperes output is then 1 milliampere. The 2 N4920 driver fronsistors are also mounted in the fan cooled tunnel to insure proper power dissipation. Resistors R1, R4, R11 and R14 between the bases equalize the voltage drop across cach compound output pair. Their values must be chosen low enough to not cause excessive voltage drop due to base currents, yet must be high enough to not require too much drive current from the preamplifier. The values chosen were 1 kilohm which will drop only 1 volt for each 1 milliampere of base current. The preamplifier current requitement is maximum when all the power supply voltage is dropped across the fout I kilohm bose drive resistors and none is across the output load. At the highest expected de voltage of 180 volts the maximum current required by the four 1 kilohro resistors is then 45 milliamperes which can be supplied easily by the driver Iransisfor mounted on the preamplifier board. The power rating required for each $1 \mathrm{kil-}$ ohm resistor at 45 milliamperes is 2,025 watis which was met by using 2 watt resistors placed in the cooling tunnel. The other components used in the power amplifier circuit and their purposes ore us follows:

1. Diodes CRI, CR3, CRII and CR13 provide protection to the $2 \mathrm{~N} 4920$ base-emitter junctions against reverse voltage spikes.

2. Diodes CR2, CR4, CR12 und CR14 are 75 volt zener diodes insuring that none of the four compound paired outpul stages can be destroyed by over voltage.

3. Resistors R2, RS, R12 and R15 are necessary to provide low resistance paths to absorb collector to base leakage currents of the output transistors when they ore turned off. 
4. Capacitors $\mathrm{Cl}, \mathrm{C} 2, \mathrm{Cl1}$ and $\mathrm{Cl} 2$ provide high frequency gain roll-off at a rate of 20 cecibe is per decade past $400 \mathrm{~Hz}$ which is the frequency at which the capacitive reactance reaches 100 ohms. This roll-off frequency is chosen to be approximately 10 times the maximum ramp rate of 2500 volts per minute (opproximately 40 volts per second). A Fourier analysis of a sawtooth wave form shows that it is made up of the fundamental and higher harmonics of diminishing amplitudes. A frequency response 10 times higher than the signal fundamental frequency will pass up to the ninth harmonic which is enough to insure o ramp purity adequate to meet requirements. Roll-off of frequencies above those required eliminates higher frequency noise components and tendencies toward high frequency oscillation common to compound feedback pairs.

\section{PREAMPLIFIER AND CURRENT CLAMP}

Preomplifier

The requirements of the preamplifier, Figure 13, page 15, are as follows:

1. Be able to work between ground and a minus 180 voit power supply.

2. Have a gain of 10 to provide a minus 100 volt output ramp with an input ramp limited to 10 volts by the 15 volt power supplies of the operational amplifier used in the ramp generator.

3. Supply sufficient output power to drive the 4 kilohm load of the power amplifier input over the required 100 volt ramp range.

4. Proyide two levels of current clamping.

Commercial operational amplifiers that could meet the preamplifier requirements were quite expensive. It was therefore decided to design a preamplifier using discrete components. The following description shows that the operation is very simflar to a commercial operational amplifier.

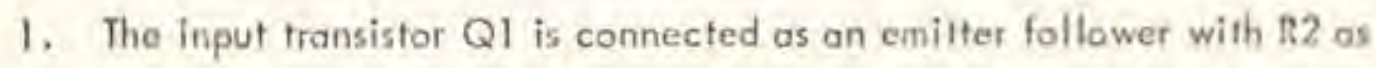
a load resistor to the minus supply voltage which is connceted to pins 10 and 11 . 
2. Resistor $R 2$ is also connected to the base of Q2 which compounded with Q3 forms a common emitter amplifier with the power amplifier base resistors us a collector load.

3. The base of Q1 input is held very near to ground (point R14) by the fact that its emitter is held to approximately -0.6 volts by the baseemitter diode of Q2. A positive going voltage applied to point $C$ will then develop a current through R1 that will appear to bo sinked to ground.

4. The current variations required by the output load voltage variation are calculated as follows:

$$
\Delta I_{e_{Q 3}}=\left(1+H_{l_{e}{ }^{3}}\right)\left(\Delta I_{b_{Q 3}}\right)
$$

but

$$
\Delta I_{\mathrm{b}_{\mathrm{Q}}}=\Delta \mathrm{I}_{\mathrm{C}_{\mathrm{Q} 2}}=\left(\mathrm{H}_{\mathrm{fe}_{\mathrm{Q} 2}}\right)\left(\Delta \mathrm{I}_{\mathrm{b}_{\mathrm{Q} 2}}\right)
$$

and

$$
\Delta I_{\mathrm{b}_{\mathrm{Q} 2}}=\Delta \mathrm{I}_{\mathrm{C} \mathrm{Q})}=\left(\mathrm{H}_{\mathrm{F}_{\mathrm{Q}} \mathrm{i}}\right)\left(\Delta \mathrm{I}_{\mathrm{b} \mathrm{Q})}\right)
$$

and

$$
\left(1+\mathrm{H}_{\mathrm{fe}}\right) \approx \mathrm{H}_{\mathrm{fe}} \mathrm{Q}_{3}
$$

so the output current

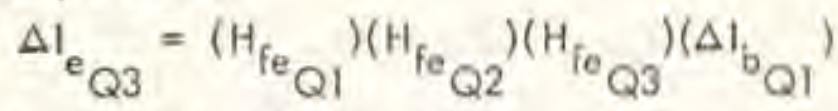

where the small signal currents of the transistors are:

$$
\begin{aligned}
& \Delta I_{b_{Q 1}} \text { - Base current of } Q 1 \text { in amperes } \\
& \Delta I_{b_{Q 2}} \text { - Base current of } Q 2 \text { in amperes } \\
& \Delta I_{c_{Q 2}} \text { - Collector current of } Q 2 \text { in amperes } \\
& \Delta I_{b} \text { - Base current of } Q 3 \text { in amperes } \\
& \Delta I_{e} \text { - Emitter current of } Q 3 \text { in amperes }
\end{aligned}
$$

and the smal! signal current gains are: 


$$
\begin{aligned}
& \mathrm{H}_{\mathrm{fe}} \text { - Current gain of Q1 in proportional ports } \\
& { }_{\mathrm{fe}} \mathrm{H}_{2} \text { - Current gain of Q2 in proportional parts } \\
& { }_{\mathrm{fe}} \mathrm{H}_{3} \text { - Current gain of Q3 in proportional parts }
\end{aligned}
$$

$\mathrm{H}_{\mathrm{fe}}$ is the small signal current gain of the transistor. The $\mathrm{H}_{\mathrm{fe}}{ }^{\mathrm{s}}$ of the transistors used are all above 100 so the quantity $\left(\mathrm{I}+\mathrm{H}_{\mathrm{fe}}\right)$ can be simplified to $\mathrm{H}_{\mathrm{fe}}$ with less than $1 \%$ error.

The rainimum $\mathrm{H}_{\mathrm{fe}}$ of the $2 \mathrm{~N} 3053,2 \mathrm{~N} 5416$ and $2 \mathrm{~N} 3439$ are all above 100 yielding a total preamplifier current gain in excess of $10^{6}$. With this high current gain it is obvious that all but one part in a million of the current in RI will flow through R. The voltage gain can then be calculated:

we have

$$
I=I_{R 1}=I_{R 3}=\frac{V_{1}-V_{G}}{R 1}=\frac{V_{G}-V_{O}}{R 3}
$$

for

$$
V_{G}=0
$$

this gives

$$
\frac{V_{O}}{V_{1}}=\frac{R 3}{R 1}
$$

where

$$
\begin{aligned}
& I \text { - Input current in amperes } \\
& I_{R 1} \text { - Current through } R 1 \text { in amperes } \\
& I_{R 3} \text { - Current through } R 3 \text { in amperes } \\
& R_{1} \quad \text { - Input resistance in ohms } \\
& R 3 \quad \text { - Feedback resistance in otms } \\
& V_{1} \quad \text { - Input voltage in volts } \\
& V_{O} \quad \text { - Output voltage in volts } \\
& V_{G} \quad \text { - Signal-ground voltage (teference) }
\end{aligned}
$$


Transistors $2 \mathrm{~N} 3439$ and $2 \mathrm{~N} 54 \mathrm{I} 6$ were chosen to sustain the 180 volts max:muin required by the preanodizer.

The power dissipation of the output transistor Q3 is maximum when its output impedance is equal to the $4 \mathrm{kilohm}$ load it must drive. This occurs during the amp when one half of the 130 volts is dropped across the 4 kilohm collector load and one half is dropped across the transistor. This power is calculated ast

$$
(90 \mathrm{~V})^{2} / 4 \mathrm{k} \Omega \approx 2 \mathrm{~W}
$$

This power dissipation is met with natural convection by a Wakefield NF 205 heat sink on the TO-5 case of Q3.

Diodes CRI and CR2 are for reverse base to emilter protection of $Q 1$ and Q2.

$\mathrm{Cl}$ provides stability by reducing the gain of $\mathrm{Ql}$ at high frequencies.

\section{Current Clamping Circuit}

Two Amp Clamp Circuit. The load current must poss through the 0.9 ohms provided by resistors $R 7, R 8$, and $R 9$ connected in parallel. When the load current reaches 2 amperes it develops 1.8 volts across the series connection of diades CR4, CR5 and the base-emitter diode of $Q 5$ providing 0.6 volts each causing them to furn on. When they furn on they provide a current flow through resistors R1, $R 4, R 11$ and $R 14$ producing a voltoge of the proper polarity to decrease the conduction of the output transistors thus clamping the output current at 2 amperes. $R 7, R 8$ and $R 9$ are precision wire wound resistors to provite stability of current clamp level.

One Amp Clamp Circuit. If the load is low enough in impodance the 2 ampere current flowing through it cannot develop a voltoge high enough to follow the oulput of the pramplifier. In this case the vollage at point $W$ will be clamped to the following voltage:

$$
V_{W}=V_{b e}+V_{R}+V_{C R 6}+V_{L}
$$

where

$$
V_{W} \text { - Potential at point } W \text { in volts }
$$




$$
\begin{aligned}
& V_{\text {be } Q 1} \text { - Base-emitter drop of } Q 1 \text { in volts } \\
& \begin{aligned}
V_{R} \quad-\text { Voltage across the parallel combination of } R 7, R 8 \text { and } R 9 \text { in } \\
\quad \text { volts, with } 2 \text { amperes current flow, } V_{R}=1.8 \mathrm{~V}
\end{aligned} \\
& V_{C R 6}-\text { Diode voltage drop of CR6 in volts, } V_{C R G}=C .6 \mathrm{~V} \\
& V_{L} \quad-\text { Voltage drop of load impedance with } 2 \text { amperes current } \\
& \text { flow, in volts }
\end{aligned}
$$

As the output of the preamplifier at point $E$ continues to rise, a voltage difference is produced across R6. This voltage in addition to the voltage drops of CR4 and CR5 and the emitter to collector voltage of Q5 (which is conducting because of the 2 ampere current clamping oction) is applied to a voltage divider consisting of R4 and R5. When the voltage difference across R4 and R5 reaches approximately 8 volts, R4 will have $8 / 13$ or 0.6 volts which will turn on transistor Q4. When Q4 furns on sufficiently its collector to emitter voltage will drop to approximately 0,3 volts. At this poinl, diodes CR4 and CR5 cannot conduct and the voltage across $R 7, R 8$ and $R 9$ decreases to this 0.3 volts plus the 0.6 volt drop of the base-emitter of Q5. This provides a current of the following value:

$$
I_{R} \quad=0.9 \mathrm{~V} / R=0.9 \mathrm{~V} / 0.9 \Omega=1 \mathrm{~A}
$$

where

$$
\begin{aligned}
& I_{R} \quad \text { - Current through resistance } R \\
& R \quad \text { - Resistance of resistors } R 7, R 8 \text { and } R 9 \text { connected in parallel }
\end{aligned}
$$

This one ampere current limit will continue as long as the output load voltage cannot follow the preamplifier autput voltage due to a low load impedance.

Diode CR6 allows the power amplifier voltage output to be reduced to zero very rapidly at the end of the ramp cycle even though there might be a voltage stored in the load. This stored voltage is sensed and the load will not be allowed to switch to the main measuring system until this woltage has decayed to a safe value. This action is described further in Subsection VI. Precision resistor RI2 produces a voltage proportional to the load current and supplies it to the current measuring circuits.

Precision resistors $\mathrm{R} 10$ and $\mathrm{R} 11$ divide the lood voltage by 25 to be used by the voltage sensing circuits. 


\section{INTEGRATOR (RAMP GENERATOR)}

The voltage ramp used to satisfy requirements $I$ and 2 is produced by an integrator circuit, Figure 14, formed by operational amplifier U2 with the input resistor $\mathrm{R} 12$ and the feedback capacitor $\mathrm{Cl}$ forming the integration time constant. The rate of voltage change at the output of $\mathrm{U} 2$ is $\mathrm{V} / 10$ of the final rate because of a gain of 10 in the preamplifier. The voltage ramp rate is a linear function of the current through $\mathrm{Cl}$, Burr-Brown Research Corporation (6). Since almost no current flows into the input of an operational amplifiet, essentially all the current through $\mathrm{Cl}$ also flows through R12. If we assume the voltage at pin 3 of $\mathrm{U} 2$ to be very close to ground and the voltoge at pin 2 to be equal to that at pin 3 because of the high gain of operational amplifier U2 then the current through R12 is defermined by the voltage applied to it from the output of UI. The output voltage of operational amplifier U1 is equal to the voltoge applied to the input resistor R6 times the ratio of the feedback resistor, $R_{F^{\prime}}$ (a variable rheostat labeled dV/dt SET) and R6. These relationships are as follows:

where

$$
\begin{aligned}
\mathrm{dV} / \mathrm{dt} & =\mathrm{H} / \mathrm{Cl} \\
\mathrm{I} & =\mathrm{kR} R_{\mathrm{F}} / \mathrm{R \sigma}
\end{aligned}
$$

$$
\begin{aligned}
& d V / d t \text { - Volfage ramp rate in volts per second } \\
& 1 \text { - Current into capacitor } \mathrm{Cl} \text { in amperes } \\
& \mathrm{Cl} \text { - Capacitance of capacitor } \mathrm{Cl} \text { in farads } \\
& 1 \quad \text { - Time in seconds } \\
& \text { R6 - Input resistance to UI in ohms } \\
& R_{F} \quad \text { - Feedback resistance (dV/dt SET) in ohms } \\
& \text { k. - Current constant in amperes }
\end{aligned}
$$

$R 6$ is selected in value to achieve the required 250 volts per minute.

When the value of $\mathrm{V}$ maximum is reached as defermined by a comparator on the logic board a positive 15 volts is applied to point 4 which furns on fransistor Q1 which shorts out $\mathrm{Cl}$ and terminates the ramp. Resistor R13 limits the discharge current of $\mathrm{Cl}$ through Ql to a sofe value. 


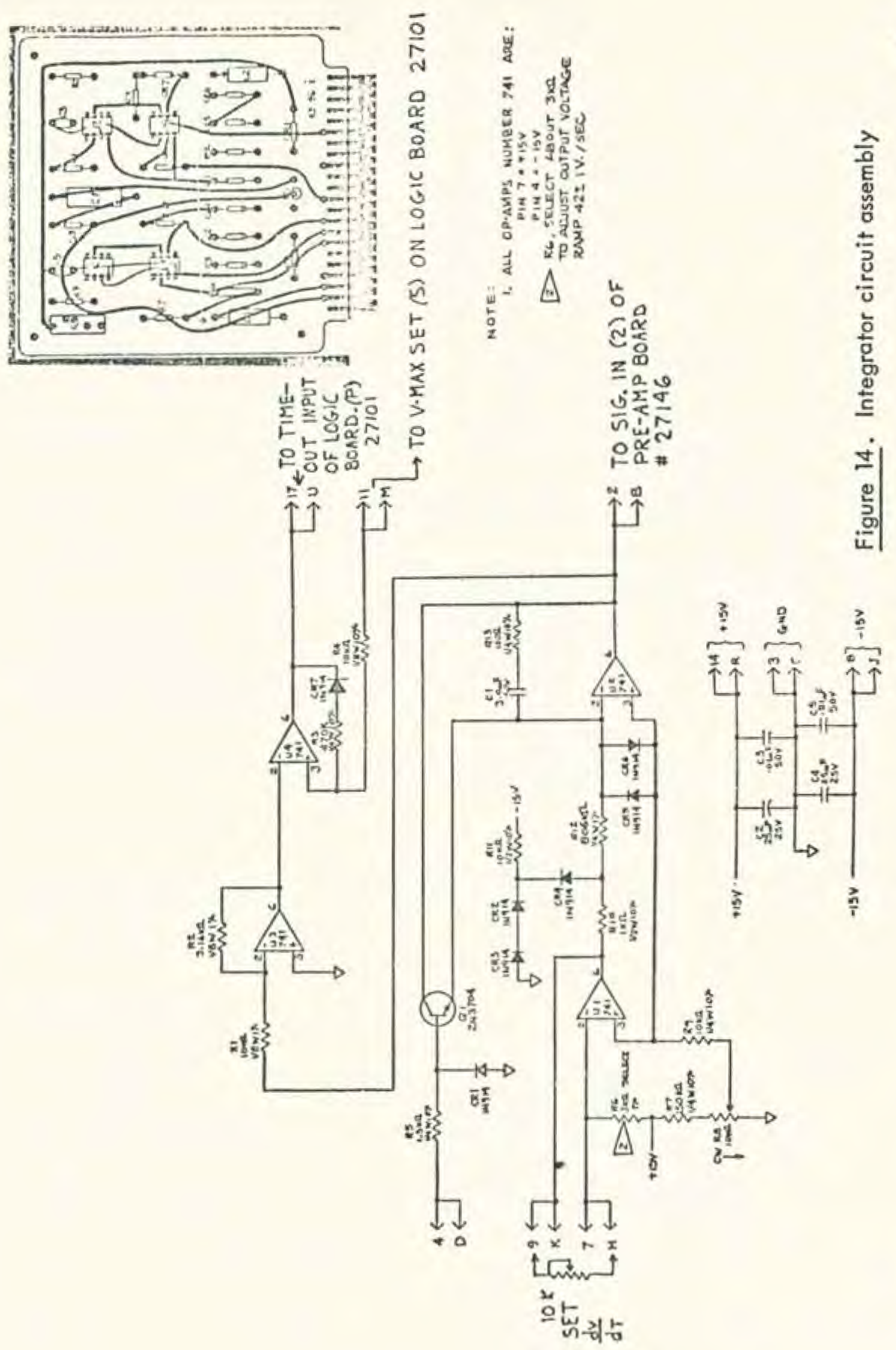


The output of $\mathrm{U} 2$ between ramps is adjusted to be a slight positive voltage that will bias the power amplifier very close to its furn on point. The voltage adjustment is necessary to compensate for the offset voltages of the integrator, preamplifier and power amplifier. The adjustment is made by providing a diode slamped -0.6 volts at the output of U1 and inserting a positive voltage variable from 0 to $+1,0$ volts to pin 3 of $U 1$ and $U 2$. This allows sufficient variation to compensate for the voltage offsets.

The voltage ramp output of $\mathrm{U}_{2}$ is fed to operational amplifier U3 where it is given a gain of approximately 0.3 by the ratio of $R 2$ to $R I$. The output of U3 is fed to $U 4$ which acts as a comparator against the $V$ maximum set voltage fed in at pin 11. A positive logic level is put out on pin 17 when the voltage out of U3 exceeds the comparator set level. Diode CR7 and resistor R3 provide hysteresis for negative outputs insuring a positive trip level of U4. This circuit shuts down the logic and terminates the ramp in a time approximately $30 \%$ longer than the set ramp time in case of a short circuited load. This circuit also causes the $d V / d t$ error light to go on, indicating that the load voltage did not build up to its set values, thus satisfying requirement 6 .

\section{$\checkmark$ CURRENT AND VOLTAGE METERING CIRCUITS}

Various meter scaling and sample and hold circuits were studied, BurrBrown Research Corporation (6), Analog Devices (7), from which the following metering method was selected.

\section{Current Metering}

A voltage proportional to the current through the load is taken across $R 12$ of the preamplifier, Figure 13, poge 15, $(0.1 \Omega)$ which is in series with the load. The voltage is applied to the signal amplifier on the metering board, Figure 15, where it is given a gain of approximately 3 becasse of the ratio of the 31.6 kilohm feedback resistor to the 10 kilohm input resistor. The signal is then passed to the sample and hold board, Figure 16, page 31, where it is given a gain of 10 by the ratio of the 50 kilohm feedback resistor to the $5 \mathrm{kilohm}$ input resistor of M3. The M3 output voltage is applied to the storage capacitor C3. At the end of the ramp

cycle relay $\mathrm{KI}$ opens before the current in the load changes. With the input 

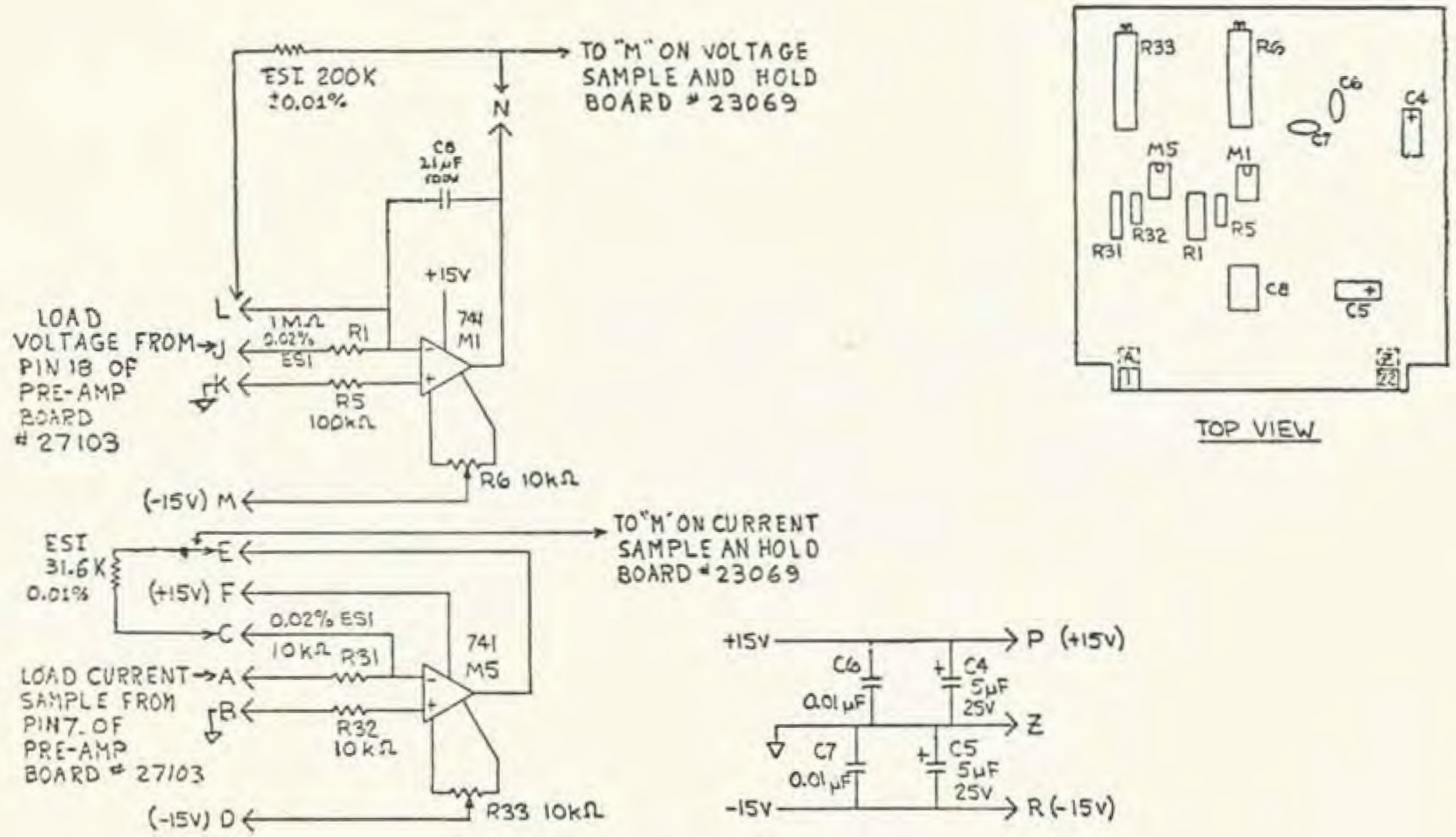

TOP VIEW

TO "M ON CURRENT

SAMPLE AN HOLD

BOARD 23069

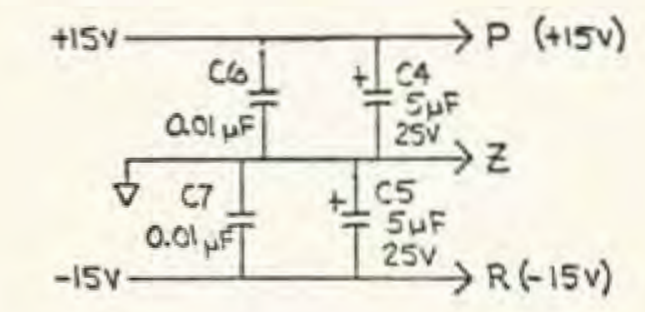

Figure 15. Metering amplifier PCB assembly 


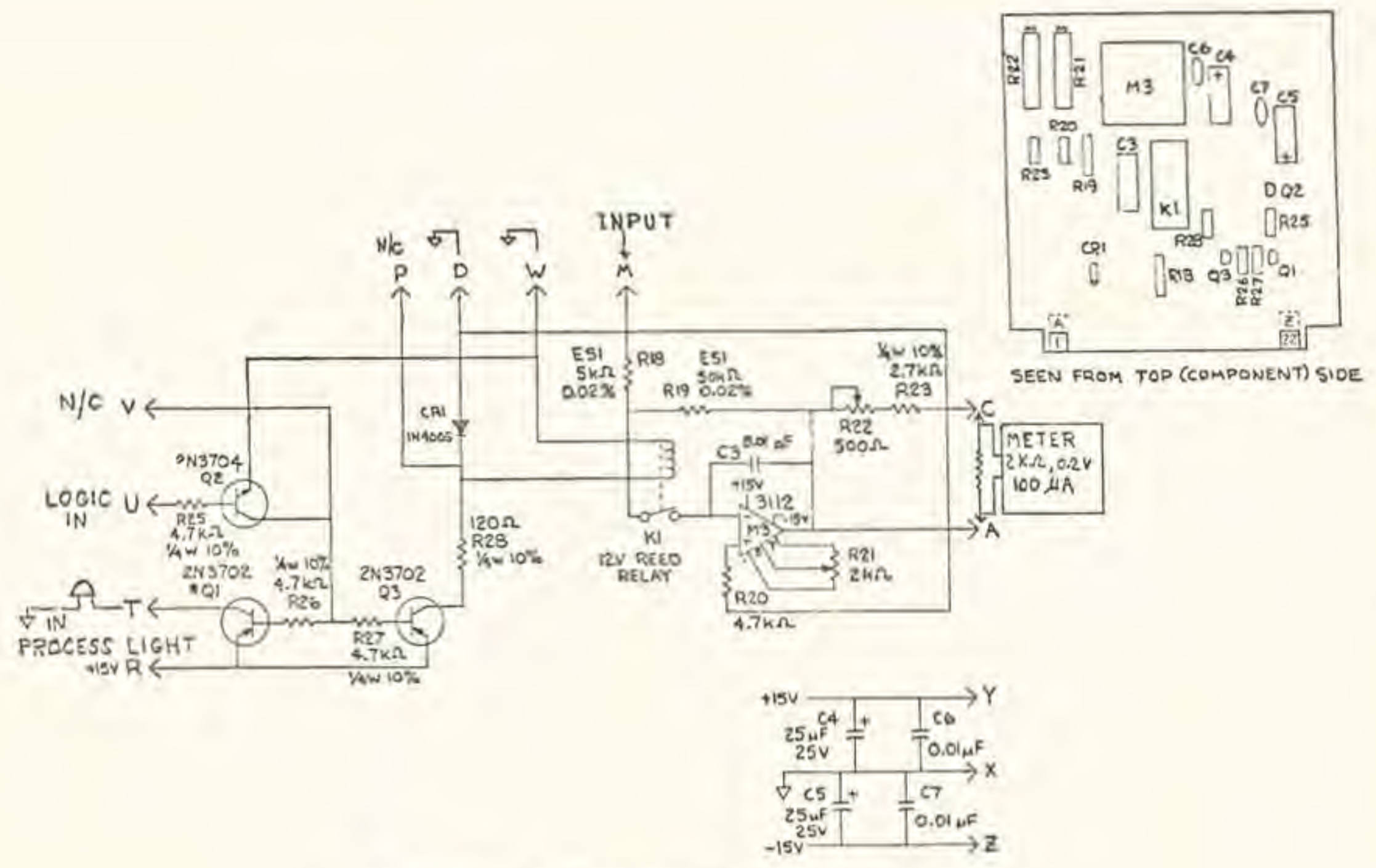

Figure 16. Sample and hold $\times 10$ (relay) PCB assembly 
resistor of operational amplifier M3 disconnected the only discharge of the voltoge on $\mathrm{C} 3$ is due to the bias current of M3. A Burr-Brown $3112 / 12 \mathrm{C}$ was chosen for $\mathrm{M} 3$ for its very low bias current of 20 picoamperes at $25^{\circ} \mathrm{C}$. The voltage decay across the 0.01 microfarad capacitor $\mathrm{C} 3$ can now be calculated as:

$$
\frac{d V}{d t}=\frac{1}{C 3}=\frac{(20)}{(0.01)} \frac{\left(10^{-1 a}\right)}{\left(10^{-6}\right)}=\frac{2 \text { millivolts }}{\text { second }}=\frac{0.120 \mathrm{~V}}{\mathrm{~min}}
$$

The panel meter used to indicate the current level has a resistance of 2 kilohms. and requires 0.2 volts to drive it full scale. A full scale output voltage from $\mathrm{M}_{3}$ of only 0.2 volts would not be high enough to provide a stable meter reading when the slorage capacitor is decaying at a rate of 0.12 volts per minute. To improve this situation the meter resistance was shunted to 68 ohms and is supplied from M3 through approximately 3 kilohms. This provides an approximate 70 to 3000 voltage division ollowing the output of $M 3$ to be

$$
(0.2 \mathrm{~V}) \frac{(3070)}{70} \approx 8.77 \text { volts }
$$

The meter reading will then decay at a rate of approximately

$$
\frac{0.12}{8.77} \times 100=1.4 \% \text { per minute }
$$

which is sufficient to maintain accurately held meter readings between ramp cycles. Relay $K 1$ is turned on during the ramp cycle by the logic board which applies a positive logic level to transistor Q2. The current through Q2 flows through the bases of Q1 and Q3 turning them on. Transistor Q3 supplies turn on current for the relay coil of K1. Transistor Q1 supplies current to the in-process light on the panel indicating that a ramp cycle is in process. The current meter reads $3 \mathrm{am}-$ peres full scole. This 3 amperes is converted to 0.2 volts across the meter as follows:

$$
V_{M}=R_{S} 1 G_{M} G_{S} G_{D}=0.21 V
$$

where

$$
\begin{aligned}
& V_{M} \text { - Meter reading in volts (proportional to current) } \\
& R_{S} \quad \text { - Resistance of shunt in ohms }(0.1 \Omega) \\
& I \quad \text { - Full scale current in amperes (3A) } \\
& G_{M} \quad \text { - Metering board gain in proportional parts (3.16) }
\end{aligned}
$$



$\mathrm{G}_{\mathrm{S}}$ - Sample and hold board gain in proportional parts (10)
$G_{D}-$ Meter resistive divider ratio in proportional ports $(68 / 3068)$

Current meter calibration is accomplished by the variable resistance $R 22$ on the current sample and hold board. The zero offset voltage of $M 3$ is reduced to zero by odjusting R21 for zero meter reading with zero signal into the sample and hold board,

The voltage offset of the operational amplifier on the metering board is reduced to zero by adjusting $R 6$ for zero meter reading with zero signal into the mefering board.

\section{Voltage Metering}

The voltage across the load is applied to a 25 to I voltage divider formed by resistors $R 10$ and $R 11$ on the preamplifier board. The gain of the metering amplifier is 0.2 determined by the 200 kilohm feedback resistor and the 1 megohm input resistor. The voltoge indicating panel meter reads 100 volts full scale and is converted to 0.2 volts across the meter as follows:

$$
v_{E}=V_{F S} G_{V D} G_{M} G_{S} G_{D}=0.177 \mathrm{~V}
$$

where

$$
\begin{aligned}
& V_{M} \text { - Meter reading in volts (proportional to voltage) } \\
& V_{F S} \text { - Full scale voltage in volts (100V) } \\
& G_{V D}-\text { Voltage divider ratio in proportional parts }(0.04) \\
& G_{M}-\text { Metering board gain in proportional parts }(0.2) \\
& G_{S}-\text { Sample and hold board gain in proportional parts (10) } \\
& G_{D} \quad-\text { Meter resistance divider ratio in proportional parts } \\
& \quad(68 / 3068)
\end{aligned}
$$

Voltage meter calibration is accomplished by the variable resistance $R 22$ on the voltage sample and hold board. 


\section{CONTROL LOGIC}

The control logic, Figure 17, satisfies requirements 5 and 7 performing the following functions when the operator pushes the start button,

1. Removes the short across the integrating capacitor so the ramp can start.

2. Switches the cross point scanner relays, Figure 18, page 36 , which transfer the resistors being anodized from the main system to the preonodizer.

3. Switches the current and voltage sample and hold circuits to the sample mode.

4. Defects when the desired V maximum is reoched and terminates the cycle by reversing the operations performed in 1 and 2 above.

5. Teminates the cycle if the ramp never reaches $V$ maximum due to the load being too low in impedance. This is done on a time out signal from the integrator as described in Subsection IV.

The logic circuits were designed using Transistor-Transistor-Logic (TTL) type logic elements, Texas Instruments lnc. (8) and Hill and Peterson (9). The circuit used to do most of the switching is the set-reset flip-flop formed by cross coupling two NAND gate sections of an SN7400 as in the NAND gates of U1 connected to the remote start control. The most desirable feature of this circuit is thot if one of the inputs is held at logic high $(+5 \mathrm{~V})$ the state of the flip-flop is changed by the first negative transition (logic low or zero volts) on the other input. Any further positive or negative transitions on that input cause no further changes in state thus eliminating any problems of switch bounce. The flip-flop is reset by removing the logic low from one input and applying a logic low to the other. The flip-flop can be connected to reset itself after a time delay to produce one pulse of a selectable width in response to a fost logic low pulse as with the NAND gotes of U2. Here a fast negative transition on pin 1 of U2 sets pin 3 to a logic high, which is applied lo pin 4. This logic high and the logic high on pin 5 supplied by pin 11 cause pin 6 to go low. The low on pin 6 is inverted to a logic high of pin 8 but the resistance-capacitance time of capacitor $\mathrm{C} 3$ and the output 


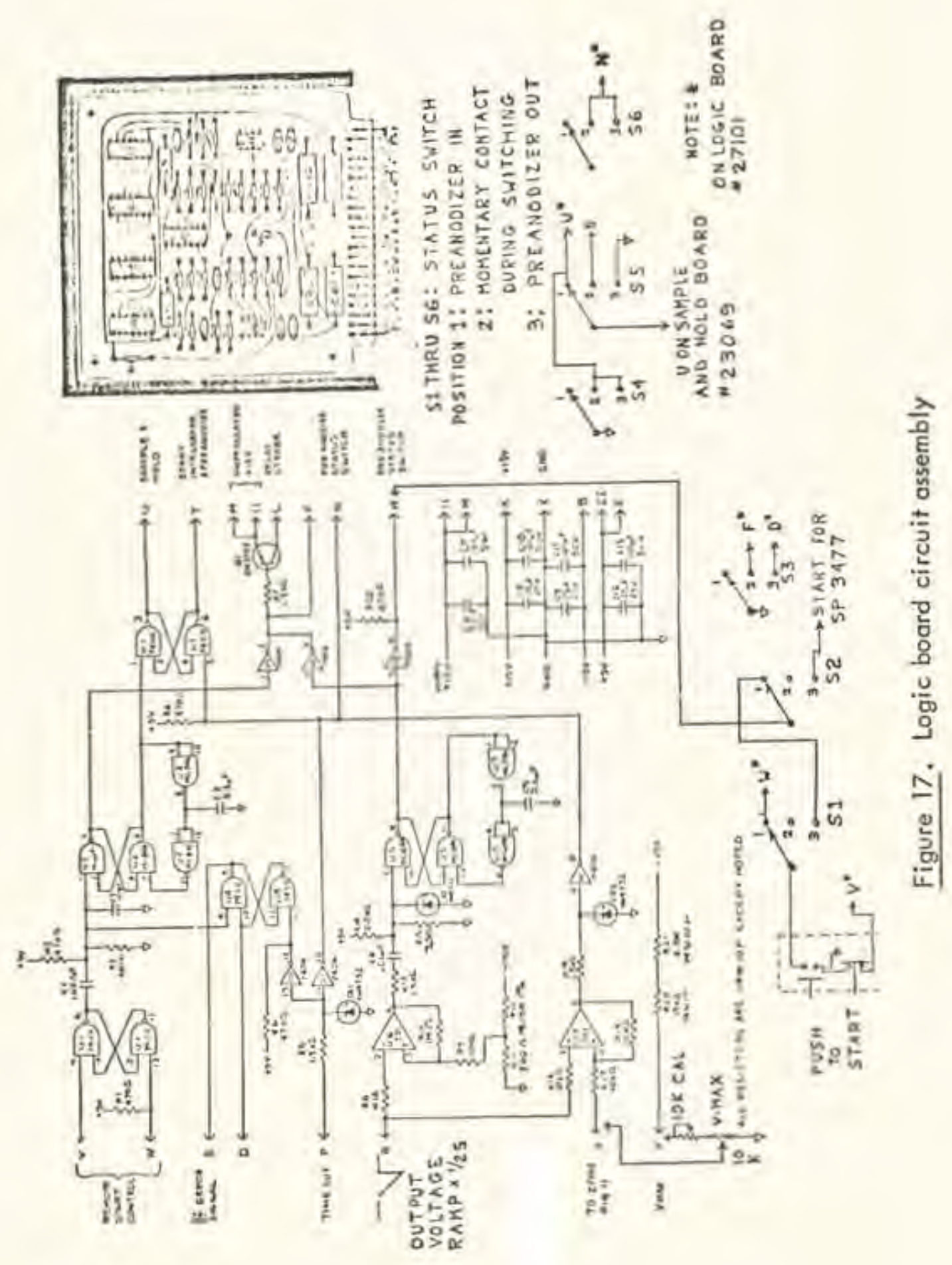



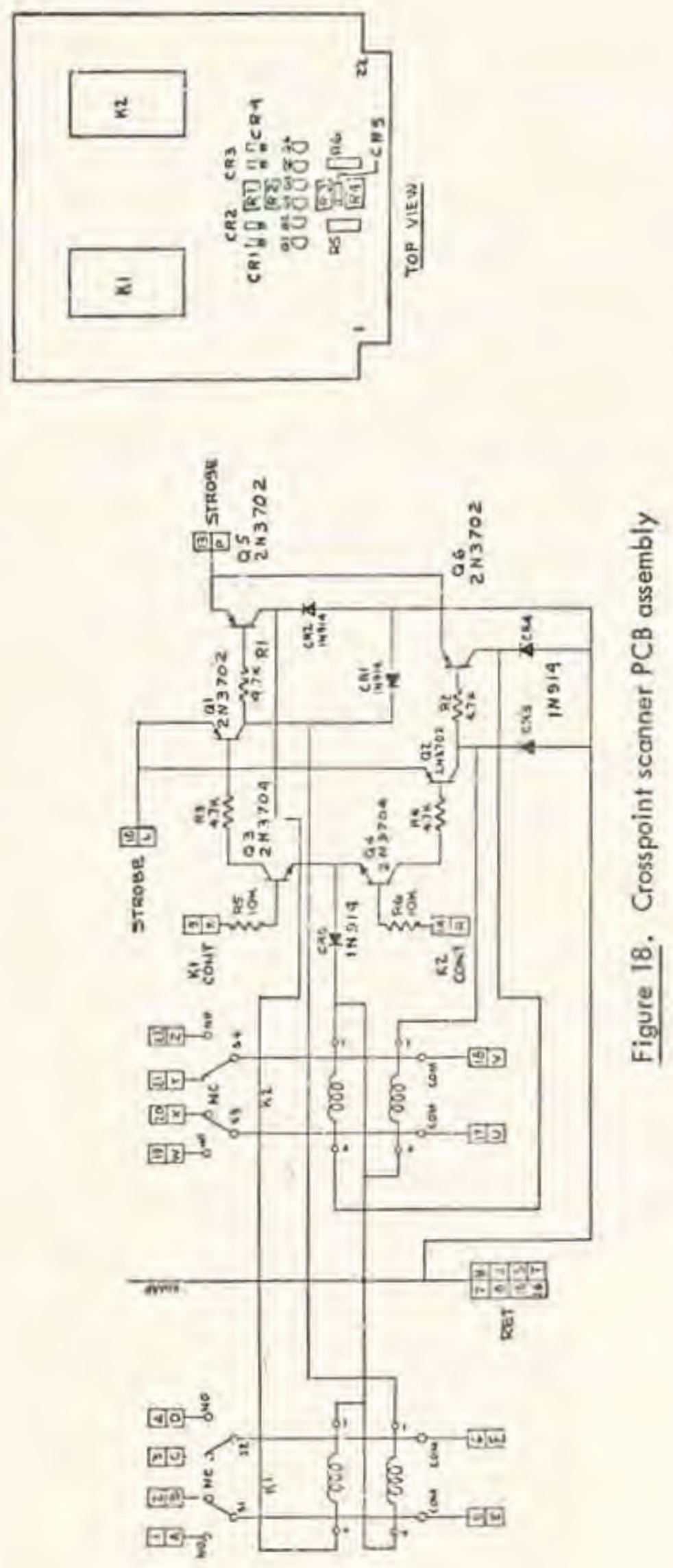
impedance of $U 2$ at pin 8 prevents pin 8 from going high for approximately 1 re sistance-capacitance time. When it does go high the high is inverted by U2 at pin 11 which provides the low required at pin 5 to reset the flip-flop.

The logic inverters SN7406 were used because their outputs are transistors with no internal collector loads. The outputs of any number of them can be connected together with a common resistor to +5 volts to form what is called a "wiredor" function. With this connection any of the inverter outputs can pull the common outpur line to a logic low.

The status switch has a detent in position 1 for preanodizer in, a momentary contact ot 2 and a detent in position 3 for preanodizer out. This switch insures that the preanodizer starts with all the set-reset (RS) flip-flops in the proper state. It also transfers the operator start switch through S1 in position 3 to the moin system and disconnects the main system start from the preanodizer start through S2. The function of sections S3, S4, S5 and S6 will be described later.

The operation of the logic board is as follows:

1. A logic low from the start button is applied to printed circuit connector pin W causing pin UT-8 to go to logic low. This logic low is formed into a fast negative transition by $\mathrm{Cl}, \mathrm{R} 2$, and $\mathrm{R} 3$. Releasing the start button resets pin 8 to a logic high.

2. The fast negative transition formed by $\mathrm{Cl}$ is applied to pin $\mathrm{T}$ of $\mathrm{U} 2$ causing a 3 millisecond logic high at pin 3 of U2 which when inverted at pin 2 of $U 3$ provides the strobe signal necessary to switch the relays and transfer the load. The 3 millisecond logic low at pin 6 of U2 is applied to pin 1 of U1 setting this Flip-flop to logic high at pin 3 of $U 1$ to signal the start of meter sampling. The logic low at pin 6 of UI removes the short across the integrating capacitor to start the ramp and provides the logic level necessary to direct the load switching relays to the proper state.

3. The fast negative transition from $\mathrm{Cl}$ is also applied to pin 9 of $\cup 4$ resetting this $\mathrm{flip}$-flop, if it were set by a time-out from the lost cycle. This flip-flop controls the $d V / d t$ error light.

4. Operational amplifier U7 forms a comparator which compares the ramp voltage (divided by the 25 to 1 voltage divider as it is applied to the 
voltage measuring circuit) and the voltage at the tap of the $\mathrm{V}$ maximum control. When the ramp voltage reaches and exceeds the $V$ maximum setting, the output of U7 goes to logic high which is inverted to a logic low at pin 8 of U3. This logic low is applied to pin 5 of U1, resetting this flip-flop which terminates the ramp and places the metering circuits in the hold condition. If the ramp never reaches the $\mathrm{V}$ maximum setting a signal at the time-out pin $\mathrm{P}$ inverted at pin 10 of U3 performs the reset function. This signal also is applied to pin 13 of U4 setting this flip-flop which lights the $\mathrm{dV} / \mathrm{dt}$ error light indicating that a normal ramp did not occur.

5. The load is not transferred from the preanodizer to the main system until the output ramp has decayed from its negative value back up to a voltage very close to zero as detected by the comparator formed by operational amplifier U6. When this occurs the flip-flop formed by U5 produces a 3 millisecond strobe pulse at pin 8 which is inverted at pin 6 of U3. This inverted pulse strobes the load switching relays so that they return the load to the main system. This inverted pulse also provides the start pulse for the main system through 52 of the status switch.

The preanodizing cycle is now complete and the unit slands by waiting for another slatt from the operator.

When the preanodizer is switched out by the status switch the following functions are performed.

1. The start button is connected to the main system through SI.

2. The start from the preanodizer to the main system is disconnected by S2.

3. $\$ 3$ in position 2 provides a relay strobe by completing the base circuit of Q1 to ground. At the same time position 2 of $\$ 4$ applies a ground to pin 4 of UI forcing pin 6 of UI to a logic high. This gives the lood relay the address to transfer the lood to the main system and signals the integrator to terminate any ramp it has started. 
4. Position 2 of $\$ 5$ holds the metering sample boards in "sample" so they can follow the terminated ramp to zero. Position 3 of 55 then locks the meters in the hold position.

5. Position 3 of $\$ 3$ insures that the flip-flop controlling the $\mathrm{dV} / \mathrm{dt}$ error light is held in its reset condition with the light out.

6. S6 holds the flip-flop formed by pins 1 to 6 of $U 1$ in its reset condition which is a low on pin $U$ and a bigh on pin $T$ of the printed circuit connector. 


\section{CALIBRATION AND FINAL EVALUATION OF PREANODIZER}

A callbration procedure was written for manufacturing checkout and customer use. Final evaluation was made after calibration of ten production units all of which met the necessary requirements.

The calibration involves adjusting the unit from the output meter circuits back toward the input integrator circuit. This insures that each section is in proper adjustment before its preceding section is added. The calibration is performed as shown in Figure 19. 


\section{EQUIPSTEST REQUIRED of equivalent:}

\section{De Voltmeter $=1$ aceuracy}

Osolitoseope 53 accurscy

1. Connect ail cables except the ac 1 lno corcl and the leadu botween the binding posts on the preenodizer output and the multiplexer.

2. Sot the SELECTOR sarteh th the IN position and eheck the following de voltagee on conneotor 31 , reasuring with respect to Pine 11 and $12:$ Pin $t=+15 \pm 0.1 \mathrm{~V}$, Pin $9=-15 \pm 0.1 \mathrm{~V}$. PIn $10=+5 \pm 0,1 \mathrm{~V}$.

3. Remove eireuit baurd As (togic board, RSt Part Na, z7t01) and earneot a Jumper

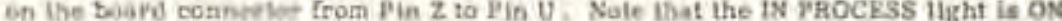

4. Remove circulf beard A7 (voltnire uample and hold: KSI Part No. 23069) and ahort the terminals of the VOLTAGE meter. Adjust the meshanical xoro if necesaary. Remove the meter short and replace tive cireuir thased.

5. Nenove eircuit board A6 tcurrent somple and holdi ESI furt No. 23069) and short out the CLRRENT metir, Adjust the meshanioul zoro If noceasary. Removo the senter sbort and règlace the eiroult hoard.

5. Renove circuit bourd A3 (metering bourd: BSI Miut No: 2J60T) and connost jugpers on the board conneotor between. Pins $1 \mathrm{f}$ and 2 and betweon Pins $\mathrm{N}$ and 2.

7. Nejust tr timmer $M 21$ on Alreult board $A 7$ for a zero rending on the VOLTAGE metor. Adjust trinmer R2L on olrcuit toard $A 6$ for a zero reading on the cunas.sT meter. Refiuve fumpers and reptace cirenil toand AS

1. Remove circuit boord A2 (preamplifion: ESt Part No. 27146) and connect jumpern on the board connector between $P$ ing 18 and $R$ and between $P$ ins 7 and $R$.

9. Adjust trimane R5 on circuil bahed A.S (nelering heard) for a nerv reading on the VOLTAGE meser. Adjust trimmer NJ3 for a kero roading on the CURRINT moter. Fentove the fumpers and replace oisouls board $\Lambda_{2}$.

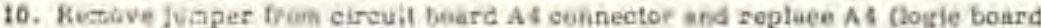
25) Part No, 27101). Put circuif board A2 (preamplifier) on an extunder and connect ac line cord to an ao outlet.
11. Measure the de voltage with the osellioscope eonnected to Junction of CR6 and KII on the preamplifler board. Adjust the average de level to -0.6 volts with trimmer $\mathrm{RS}$ on elroult board $\mathrm{AJ}$ (integrator). There is approxtmately $0.2 \mathrm{~V} \mathrm{p}-\mathrm{p}$ ripple at this polnt whtoh is normal for a no-lead condition: bafuat the $-0.6 \mathrm{~V}$ level to the eenter of the ripple, flemove the estender and roviace eirewit bont $\mathrm{A}^{3}$.

12. Remuve the extender and reploce cireull board A3. Mace eireult board $\mathrm{At}$ on the exteader and conneot the onoliloncope to the OUTrUT binding posts with the seope ground Inad connectod to the "*" binding post and the scope probe to the "-"

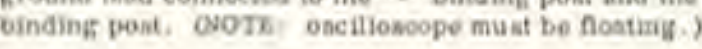

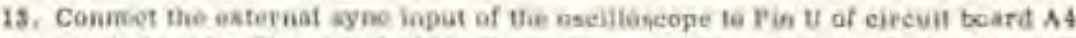

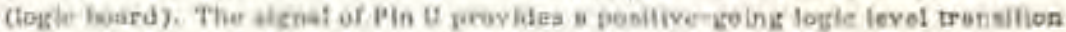
at the besimims of the voltage ramp eyele, Set the eseillonoope time base for $0.5 \mathrm{a} / \mathrm{div}$, and the vertical sonsitivity for $20 \mathrm{~V} / \mathrm{div}$.

14. Set the $\mathrm{v}_{\max }$ enompat to ag $\mathrm{V}$ and the dv/st eantral to $2400 \mathrm{~V} /$ win (these sellings will posulf in $* 1$ s ramp). Start a rump eycle by pressing the KEYOTE START button, then adjust the $\mathrm{V}_{\operatorname{mas}}$ triminer (locoted behind the front panel nest the CURRENT mutor) for $8052 \mathrm{~V}$ as masaurud on the oxollosoope. Ramp tise should

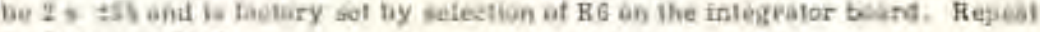
eyele an required.

15. After comploting stop 14, adjuat wimmer $R 22$ on the voltage und sample board (A7) for wo $\mathrm{V}$ on die vot.tact neter, it may be heeensary to repeat vie cycle severd times to make bis nefustment.

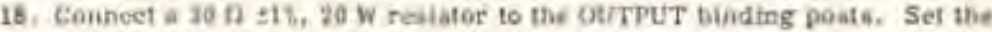
gurlitoscope lime bae for 0.1 s/div, and the verliesi sensitivily lo $3 \mathrm{~V} / \mathrm{dir}$.

19. Adjuit the $\mathrm{V}_{\text {mis }}$ sontrol for $20 \mathrm{~V}$. Start the ramp eycle sod adjuat trimmer hat on

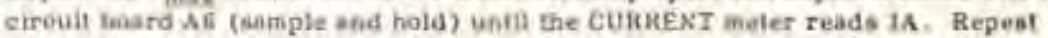
live cycle as needed

18. Nemove the $30 \mathrm{a}$ resintor and connect a whort acrosi the OuzPuT binding posts. Adjust the dv/d control $6100 \mathrm{~V} / \mathrm{Bi}$ in and start a raitip cjole. Current shavtd rise to approximalely $2 A$ (first current limit), then drop to lesa than LA (steond current linait). The dv/dt error light should come on at the end of the ramp eycle.

\section{Figure 19. Calibration procedure}




\section{CONCLUSION}

The design of the preanodizer described in this thes is was an interesting experience which required study in several areas of electronic technology. These areas included:

1. Power supply design

2. Signal generation

3. Power amplification of the generated signal

4. Metering circuit design

5. Logic and control circuil design

Each section required a search of current literature for suitable electronic circuits and devices. The courses taken while fulfilling the Master's Degree requirements were necessary for this project. The ability to approach a project of this complexity would have been very difficult without the courses in electronics, logic design, and mathematics taken of Portland State University.

Since there are many different ways to accomplish a given task the final choices were made on a bosis of the highest reliability and optimum performance. After the circuit design decisions were made, many of the circuits had to be built and tested prior to a final choice. Several design changes were made as a result of these tests.

The author's project responsibilities extended from the circuit design stage through hardware design into the production phase and then into final test and calibration.

After completion of the design a production run of ten units was made, tested and shipped to the Western Electric Compgny. These unils have been in service for approximately two years and as of this date none of them have experienced o failure.

Future projects assigned to the author will certainly benefit from the knowledge and experience gained on this project. 


\section{BIBLIOGRAPHY}

1. Berry, Robert W., Peter M. Hall and Murray T. Harris. Thin Film Technology. D. Van Nostrand Company, Inc,, 1968.

2. Boylestad, Robert and Louis Washelsky. Electronic Devices and Circuit Theory. Prentice-Hall, Inc., 1972

3. Radio Corporation of America, 1969. Power Circuits. RCA Technical Publication.

4. Cowles, Laurence G. Analysis and Design of Transistor Circuits.

D. Van Nostrand Company, Inc., 1966.

5. Cutler, Phillip. Semiconductor Circuit Analysis. McGraw-Hill Book Company, 1964.

6. Operational Amplifiers; Design and Applications. Graeme, Jerald G., Editor, Part I, Gene E. Tabey, Editor, Part 2, and Lawrence P. Huelsman, Consulting Editor. Burr-Brown Researeh Corporation, 1971. McGraw-Hill Book Company.

7. Analog Devices. Nonlinear Circuits Handbook. Analog Devices, 1974 .

8. Texas Instruments, Inc,, 1971. Designing With TTL Integrated Circuits. IC Applications Staff of Texas Tnstruments, Ine. McGraw-Hill Book Compony

9. Hill, Fredrick J. and Gerald R. Peterson. Introduction to Switching Theory and Logic Design. John Wiley and Sons, Ine.,1968. 